Draft 8/15/18

Forthcoming Yale Law Journal

\title{
REGULATORY BUNDLING
}

\author{
Jennifer Nou and Edward H. Stiglitz*
}

Regulatory bundling consists of the ability of administrative agencies to aggregate and disaggregate rules. Agencies, in other words, can bundle what would otherwise be multiple rules into just one. Conversely, it can split one rule into several. This observation parallels other recent work on how agencies can aggregate adjudications and enforcement actions, but now focuses on the most consequential form of agency action: legislative rules. The topic is timely in light of a recent executive order directing agencies to repeal two regulations for every new one promulgated. Agencies now have a greater incentive to pack regulatory provisions together for every two rules it can repeal.

This Article explores the positive determinants and normative implications of regulatory bundling. The empirical analysis reveals that agencies have been increasingly engaging in regulatory bundling for the last two decades. More generally, bundling behavior varies widely across different administrative agencies, and agencies appear to include more subjects in their final, as opposed to proposed, rules. These findings, in turn, raise significant normative concerns that could be addressed through a suite of tools novel to the administrative state: single-subject rules, line-item vetoes, and innovative uses of more traditional doctrines of judicial review. Whether some of these tools should be adopted, however, requires further empirical assessment of regulatory bundling's causes and consequences.

\footnotetext{
* Professor, University of Chicago Law School; Associate Professor of Law and Jia Jonathan Zhu and Ruyin Ruby Yu Sesquicentennial Fellow, Cornell Law School, respectively. Many thanks to Bruce Ackerman, Zach Clopton, Sean Farhang, Michael Gilbert, Tom Ginsburg, Emily Hammond, Aziz Huq, Ronald Levin, Anne O’Connell, Lee Fennell, Ricky Revesz, Kyle Rozema, and David Zaring for helpful comments and conversations. Thanks also to the participants in the New Frontiers in the Empirical Study of Agency Policymaking Conference at University of Wisconsin-Madison; the Political Economy and Public Law Conference at Cornell Law School; the AALS session on New Voices in Administrative Law; and faculty workshops at the University of Chicago Law School, Cornell Law School [more acknowledgements to come]. Julia Bradley, Colleen Guo, Nathaniel Ludewig, Eileen Prescott and Paul Rogerson provided superb research assistance.
} 


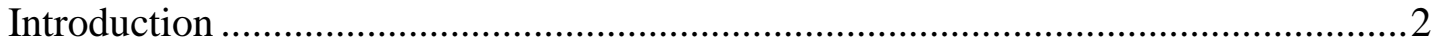

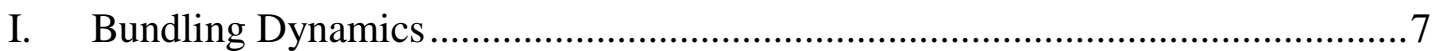

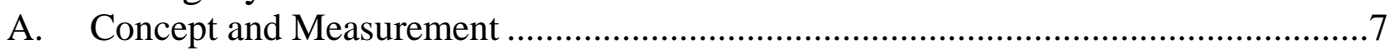

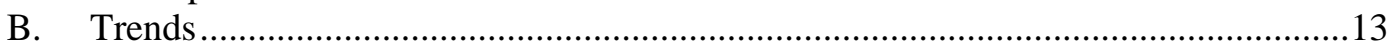

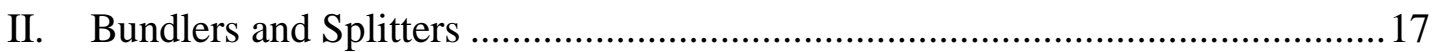

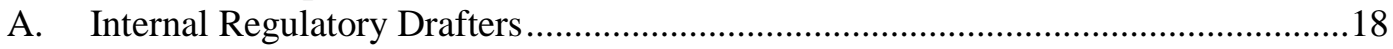

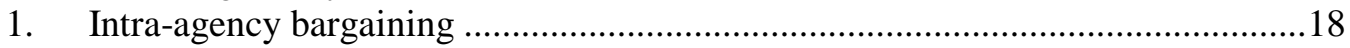

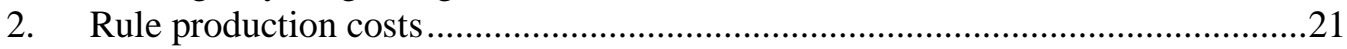

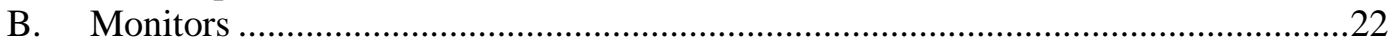

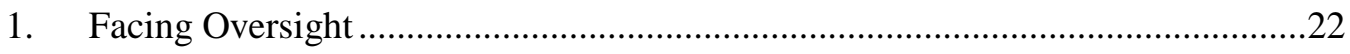

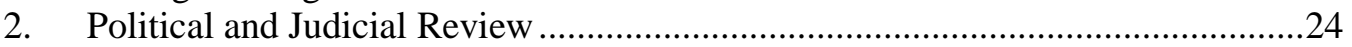

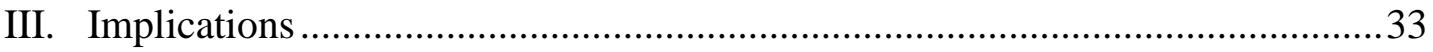

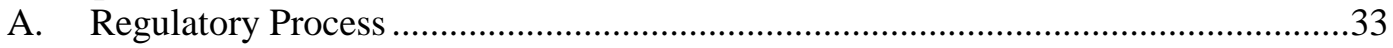

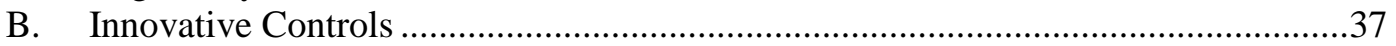

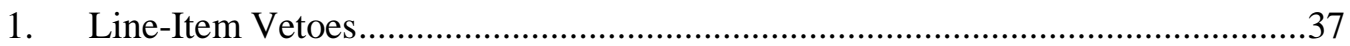

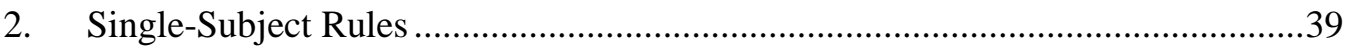

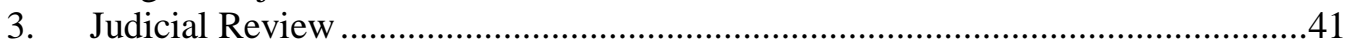

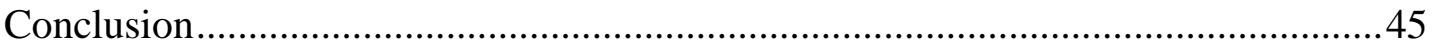

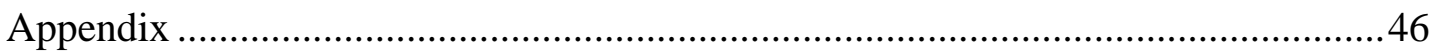

\section{Introduction}

Administrative agencies have immense discretion in how to make policy. They can, for example, choose their form of action: whether a rule, an adjudication, an enforcement, or guidance document. ${ }^{1}$ For decades, commenters have analyzed the positive and normative tradeoffs of each. ${ }^{2}$ More recently, scholars have become attentive to the ways in which these forms can be aggregated. Some, for example, have debated adjudicatory aggregation through administrative class actions. ${ }^{3}$ Others

\footnotetext{
${ }^{1}$ See M. Elizabeth Magill, Agency Choice of Policymaking Form, 71 U. CHI. L. REV. 1383, 1383-84 (2004) (noting that a "legislative rule, administrative adjudication, judicial enforcement, or guidance" document usually comprises the "standard set" of agency policymaking forms).

${ }^{2}$ See, e.g., Jerry L. Mashaw \& David L. Harfst, Regulation and Legal Culture: The Case of Motor Vehicle Safety, 4 YALE J. REG. 257, 273-74 (1987); Magill, supra note 1; Glen O. Robinson, The Making of Administrative Policy: Another Look at Rulemaking and Adjudication and Administrative Procedure Reform, 118 U. PA. L. REV. 485, 512 (1970); David L. Shapiro, The Choice of Rulemaking or Adjudication in the Development of Administrative Policy, 78 HARV. L. REV. 921 (1965).

${ }^{3}$ See, e.g., Shannon M. Grammel \& Joshua C. Macey, The Costs of Aggregating Administrative Claims, 70 Stan. L. Rev. OnLINE 123 (2018); Michael D. Sant'Ambrogio \& Adam S. Zimmerman, The Agency Class Action, 112 CoLuM. L. REV. 1992, 1999 (2012) (arguing "that agencies should
} 
have remarked upon "crackdowns," or the ways in which enforcement actions can be pursued all at once. ${ }^{4}$ This lens has proven fruitful in shedding new light on agency discretion by drawing upon rich analogies to other areas of the law such as civil procedure where aggregation and its discontents are common themes. ${ }^{5}$

Puzzling, then, that more attention has not been paid to the ways in which agencies can aggregate perhaps the most consequential tool at their disposal: legislative rules. ${ }^{6}$ Legislative rules, like statutes, bind entire classes of individuals. ${ }^{7}$ They too can be combined in multiple ways - a phenomenon that we refer to as regulatory bundling. Regulatory bundling refers to the ability of agencies to choose the scope of a single rulemaking, the number of discrete issues to resolve at a given point in time. Bundling decisions can occur at all stages of the rulemaking process, from drafting to implementation to litigation. An agency, for example, can bundle some decisions at the proposed rule stage, only to split them into distinct final rules. It can then re-aggregate those issues and revise them through a subsequent regulation.

Consider some examples:

- The Occupational Safety and Health Administration (OSHA) traditionally regulated a single substance at a time. ${ }^{8}$ Its Air Contaminants Standard rule, however, addressed 428 substances — from sulfur dioxide, to styrene, to

adopt aggregation procedures, like a civil class action, to resolve common claims raised by large groups of people in administrative courts"); Michael Sant'Ambrogio \& Adam S. Zimmerman, Inside the Agency Class Action, 126 YALE L.J. 1634 (2017).

${ }^{4}$ See, e.g., Mila Sohoni, Crackdowns, 103 VA. L. REV. 31, 33 (2017) (defining a "crackdown" as an "executive decision to intensify the severity of enforcement of existing regulations or laws as to a selected class of offenders or a selected set of offenses"); Steven Wisotsky, Crackdown: The Emerging "Drug Exception' to the Bill of Rights, 38 HASTINGS L.J. 889, 894 (1987) (describing an "extraordinary enforcement program" against drugs that "set new records in every category of measurement - drug seizures, investigations, indictments, arrests, convictions, and asset forfeitures"). ${ }^{5}$ See, e.g., Samuel Issacharoff, Private Claims, Aggregate Rights, 2008 SUP. CT. REV. 183 (2008).

${ }^{6}$ To be sure, the legal literature has recognized that rules can be bundled and split, but has not given the topic sustained attention. See, e.g., Cary Coglianese \& Daniel E. Walters, Agenda-Setting in the Regulatory State: Theory and Evidence, 68 ADMIN. L. REV. 93, 104 (2016) (observing that some "statutes give greater discretion to agencies to pace their progress in implementing bundles of rules by simply requiring the agency to finish all of its rulemaking responsibilities by a certain date"); Note, OIRA Avoidance, 124 HARV. L. REV. 994, 1015 n. 12 (2011) (noting possibility that agencies split rules into parts to avoid review by the Office of Information and Regulatory Affairs). Relatedly, Abbe Gluck, Anne O'Connell, and Rosa Po remark upon what they call "omnibus rules." Omnibus rules can be understood as a subset of the larger category of what we call bundled rules, which includes rules with unrelated and related provisions. See Abbe R. Gluck, Anne Joseph O'Connell and Rosa Po, Unorthodox Lawmaking, Unorthodox Rulemaking, 115 COLUM. L. REV. 1789 (2015). .

${ }^{7}$ See Kenneth Culp Davis, Administrative Rules-Interpretative, Legislative, and Retroactive, 57 YALE L. J. 919, 919 (1948) (noting that "rule-making is the part of the administrative process that resembles a legislature's enactment of a statute").

${ }^{8}$ Am. Fed'n of Labor \& Cong. of Indus. Organizations v. Occupational Safety \& Health Admin., U.S. Dep't of Labor, 965 F.2d 962, 971 (11th Cir. 1992) (noting that "[u]nlike most of the OSHA standards previously reviewed by the courts, the Air Contaminants Standard regulates not a single toxic substance, but 428 different substances"). 
wood and grain dust - all at once. ${ }^{9}$ After a court struck down the bundled regulation, OSHA was unable to revise any of the individual standards, despite efforts to rebundle them in new ways. ${ }^{10}$

- The Environmental Protection Agency (EPA) initially set out to regulate greenhouse gases under the Clean Air Act through one rulemaking. ${ }^{11}$ After a change in presidential administration, however, the agency instead decided to issue four separate rules addressing different subjects. ${ }^{12}$ The first determined that carbon dioxide "endangered" the public. ${ }^{13}$ The second regulated auto emissions in light of that finding. ${ }^{14}$ The third dealt with "triggered" permitting requirements for stationary sources ${ }^{15}$ while the fourth "tailored" the permitting requirements to the largest carbon emissions sources. ${ }^{16}$ All of these regulatory decisions could have been packaged into one rulemaking, but the EPA instead split them into four. ${ }^{17}$

- In response to patient deaths in Fialuridine clinical trials, the Food and Drug Administration (FDA) proposed a rule establishing new reporting requirements for human drug and biological products as well as investigational new drug applications. ${ }^{18}$ It delayed the issuance of the final rule in response to heavy criticism from commenters, however, and considered breaking up the proposed rules into three separate final rules instead. ${ }^{19}$ The FDA ultimately decided to issue guidance documents addressing some of the issues. ${ }^{20}$

${ }^{9}$ Id. See 54 Fed. Reg. 2332-2983 (Jan. 19, 1989).

${ }^{10}$ See John Howard, Osha Standards-Setting: Past Glory, Present Reality and Future Hope, 14 EMP. RTS. \& EMP. POL'Y J. 237, 250 (2010) (noting that since the adverse court decision, "OSHA has been unable to reestablish new [standards] for the substances covered in its former air contaminants" rule despite effort to issue new rule covering twenty substances).

${ }^{11}$ See Michael S. Greve \& Ashley C. Parrish, Administrative Law Without Congress, 22 GEO. MASON L. REv. 501, 507 (2015); Gluck, O’Connell \& Po, supra note 6, at 1806.

${ }^{12}$ Greve \& Parrish, supra note 12, at 507.

${ }^{13}$ Endangerment and Cause or Contribute Findings for Greenhouse Gases Under Section 202(a) of the Clean Air Act, 74 Fed. Reg. 66,496 (Dec. 15, 2009).

${ }^{14}$ Light-Duty Vehicle Greenhouse Gas Emission Standards and Corporate Average Fuel Economy Standards; Final Rule, 75 Fed. Reg. 25,324 (May 7, 2010).

${ }^{15}$ Reconsideration of Interpretation of Regulations that Determine Pollutants Covered by Clean Air Act Permitting Programs, 75 Fed. Reg. 17,004 (Apr. 2, 2010).

${ }^{16}$ Prevention of Significant Deterioration and Title V Greenhouse Gas Tailoring Rule, 75 Fed.

Reg. 31,514 (June 3, 2010).

${ }^{17}$ Greve \& Parrish, supra note 12, at 507.

${ }^{18}$ Adverse Experience Reporting Requirements for Human Drug and Licensed Biological Products, 59 Fed. Reg. 54046-01 (Oct. 27, 1994). See FDA Defers to International Harmonization in Adverse Event Reporting Proposal, 3 No. 3 Guide to Good Clinical Practice Newsl. 6 (Dec. 1995).

${ }^{19} \mathrm{Id}$.

${ }^{20}$ See Expedited Safety Reporting Requirements for Human Drug and Biological Products, 62 Fed. Reg. 52237 (Oct. 7, 1997) (noting that FDA "has decided to withdraw the proposed amendments to the IND requirements for clinical study design and conduct and annual sponsor reporting. The agency will, instead, develop a guidance document providing recommendations on study design and monitoring of investigational drugs used to treat serious and potentially fatal illnesses.") 
Each of these scenarios illustrates a form of bureaucratic discretion - regulatory bundling — with underexplored implications for the administrative state.

Indeed, the phenomenon has newfound significance given a recent Trump Administration executive order aimed at reducing regulatory costs. ${ }^{21}$ The order, among other things, directs agencies to repeal two regulations for every significant new one promulgated - often referred to as the " 2 for 1 " requirement. ${ }^{22}$ Executive agencies now have a greater incentive to pack more regulatory provisions into one rule, for doing so would deliver more bang for the buck. Assuming a fixed amount of offsetting rules at a given time, in other words, an agency can regulate more by aggregating provisions into a single rulemaking. ${ }^{23}$ If the agency splits them, by contrast, it would be forced to find yet another two rules to repeal. One would thus expect to see more regulatory bundling after the executive order went into effect.

As further motivation, consider parallel scholarly observations about the legislative process. Social scientists have long studied the phenomenon of omnibus bills in Congress, through which legislators bundle numerous, often unrelated, provisions. ${ }^{24}$ Positive theories propose that omnibus vehicles allow legislators to advance partisan agendas; engage in distributive logrolling; or pass otherwise unpopular measures. ${ }^{25}$ Normative reformers, in turn, have often called for statutory unbundling. Single-subject rules found in many state constitutions, for example, limit bills and referenda to one subject. ${ }^{26}$ The line-item veto similarly facilitates statutory unbundling by the executive branch. ${ }^{27}$

This Article explores analogous insights in the regulatory context in the hopes of spurring a broader research agenda akin to the decades of studies pursued in the legislative arena. The effort here is primarily one of theory-building: to that end, some of the preliminary empirical analyses are intended to generate hypotheses for more rigorous testing in future work. This study also attempts to complicate existing debates about agency behavior. Take, for example, rule counts. Popular media and academic studies often rely on them to convey the magnitude of agency regulatory

${ }^{21}$ Exec. Order No. 13,771, 82 Fed. Reg. 9,339 (Feb. 3, 2017).

${ }^{22} I d$.

${ }^{23}$ There is, of course, an important dynamic element depending on the relevant time horizons, Given a finite store of minor regulations sacrificed to be part of the two regulations repealed, in the long run, agencies will have to sacrifice their bundled regulations in order to issue a new regulation. In this manner, bundling rules in response to the executive order could backfire, in a sense.

${ }^{24}$ See, e.g., GLEN S. KRUTZ, HitCHING A Ride 45 (2001); BARBARA SinClaIR, UnORTHOdOX LAWMAKING 112 (4th ed. 2012); Johanna M. Goertz, Omnibus or Not: Package Bills and Single-Issue Bills in a Legislative Bargaining Game, 36 SOC. CHOICE \& WeLFARE 547 (2011), Glen S. Krutz, Getting Around Gridlock: The Effect of Omnibus Utilization on Legislative Productivity, 25 LEG. STUD. Q. 533 (2000); Glen S. Krutz, Tactical Maneuvering on Omnibus Bills in Congress, 45 AM. J. POL. SCI. 210 (2001).

${ }^{25}$ See KRUTZ, supra note 24, at 32-33.

${ }^{26}$ See National Conf. OF State Legislators, Single-SubJeCt Rules, available at http://www.ncsl.org/research/elections-and-campaigns/single-subject-rules.aspx. Many of them require the single subject to be included in the bill's title. WILLIAM ESKRIDGE et al., LEGISLATION \& REGULATION 309 (2014).

${ }^{27}$ This mechanism currently permits state governors in about forty-three states to veto "items" from appropriations bills, subject to legislative override. Id. at 314 . 
activity. ${ }^{28}$ But a single rule can set wide-ranging standards or address narrow compliance issues. It can deal with technical or routine matters, with temporary effect. ${ }^{29}$ It can be deregulatory in whole or part. ${ }^{30}$ Rule-counts are thus often misleading indicators of regulatory activity.

Appreciating agency bundling, by contrast, helps to refine thinking about the relevant units of analysis. If compliance burdens are a concern, for instance, it may be more sensible to measure costs rather than tally rules. Understanding the phenomenon also enrichens and complements work on the strategic timing of agency decisions and the more dynamic aspects of rulemaking behavior. ${ }^{31}$ Agencies can simply delay controversial provisions, for example, by splitting them from a particular rule to save for future rulemakings.

Part I analyzes the concept and operationalization of regulatory bundling. It uses a unique dataset obtained from nearly twenty years of rulemaking across a wide range of agencies to provide an initial descriptive picture of the dynamic. ${ }^{32}$ The results suggest that bundling is increasingly common. Agencies seem more likely to

${ }^{28}$ See, e.g., The Regulatory Tsunami - How a Tidal Wave of Regulations Is Drowning America, Speech, Thomas J. Donohue, President and C.E.O., Chamber of Commerce to The Des Moines Rotary Club (Oct. 7, 2010) (claiming that "approximately 4,000 rules from nearly 70 departments and agencies filled the regulatory pipeline in 2008"), available at

http://www.uschamber.com/press/speeches/2010/regulatory-tsunami-how-tidal-wave-regulationsdrowning-america. Academic scholarship also relies on rule-counts, though is often aware of this measure's limitations. See, e.g., Jason Webb Yackee \& Susan Webb Yackee, Testing the Ossification Thesis: An Empirical Examination of Federal Regulatory Volume and Speed, 1950-1990, 80 GEO. WASH. L. REV. 1414, 1445 (2012) (describing their database as "essentially count[ing] the number of NPRMs and final rules issued by each agency over time"); Anne Joseph O'Connell, Political Cycles of Rulemaking: An Empirical Portrait of the Modern Administrative State, 94 VA. L. REV. 889, 922 n.1 (2008) (acknowledging that a database "looking at counts of various rulemaking activities ... because they are aggregate measures, miss many details of individual rulemakings").

${ }^{29}$ See, e.g., Department of Homeland Security, Coast Guard, "Drawbridge Operation Regulations; China Basin, San Francisco, CA," 78 Federal Register 19585, April 2, 2013 (specifying a provisional deviation from a bridge operating schedule).

${ }^{30}$ See Jerry L. Mashaw, Improving the Environment of Agency Rulemaking: An Essay on Management, Games, and Accountability, LAW \& CONTEMP. PROBS., Spring 1994, at 198 n.41.

${ }^{31}$ See Jacob E. Gersen \& Anne Joseph O'Connell, Hiding in Plain Sight? Timing and Transparency in the Administrative State, 76 U. CHI. L. REV. 1157 (2009); Rachel Augustine Potter, Slow-Rolling, Fast-Tracking, and the Pace of Bureaucratic Decisions in Rulemaking, 79 J. PoL. 841 (2017); Wendy Wagner, William West, Thomas McGarity \& Lisa Peters, Dynamic Rulemaking, 92 N.Y.U. L. ReV. 183 (2017).

32 Uniquely, the dataset draws directly from the Federal Register, which is the government's "official daily publication for rules, proposed rules, and notices of Federal agencies and organizations." See Gov. Printing Off., About Federal Register, available at http://www.gpo.gov/help/about_federal_register.htm. Since agencies must publish in its pages for their rules to gain legal effect, the Federal Register provides the most comprehensive look possible at agencies' rulemaking behavior. See 44 U.S.C. $\$ 1507$ (2000). See O'Connell, supra note 28, at 928 ("Publication in the Federal Register is the official means of notifying the public of new regulations, and agency activity cannot be hidden if agencies expect anyone to comply with their rules."); Randy S. Springer, Note, Gatekeeping and the Federal Register: An Analysis of the Publication Requirement of Section 552(a)(1)(D) of the Administrative Procedure Act, 41 ADMIN. L. REV. 533, 544 (1989) ("Agency documents that fall within the provisions of the publication rule of section 552(a)(1)(D) and are not so published are ineffective against a party without actual notice."). 
bundle issues in their rulemaking efforts today than they were even a short time ago. Moreover, agencies appear to adopt a wide variety of practices with respect to bundling: some bundle a great deal, and others do so rarely.

Part II, in turn, explores the various actors internal and external to the agency that likely influence the agency's bundling decision. It considers the regulatory drafting process within agencies as well as how political and judicial monitors themselves can package and split rules. Basic empirical analysis suggests that independent and executive agencies bundle differently, perhaps reflecting the meaningful influence of presidential review coordinated by the Office of Information and Regulatory Affairs (OIRA). In addition, executive agencies appear to slightly bundle more under divided government, that is, when Congress is of a different political party. Elections also seem to have an effect in favor of less bundling.

Finally, Part III acknowledges concerns that regulatory bundling raises about political accountability, public participation, and legislative fidelity. Regulatory bundling may allow agencies to overwhelm political and judicial overseers, as well as short-circuit the notice and comment process. Indeed, our analysis finds that agencies appear to bundle more subjects into final, as opposed to proposed, rules. At the same time, this Part recognizes that bundling yields benefits as well, so recommends further empirical work to assess the tradeoffs. In doing so, it highlights the possibilities and pitfalls of regulatory single-subject rules and the functional lineitem veto exercised by the President through OIRA. Courts may also have a limited role to play in policing bundling through arbitrary-or-capricious review and the logical outgrowth doctrine.

\section{Bundling Dynamics}

Scholars have long engaged the question of why regulations exist. ${ }^{33}$ Far less studied, however, is the question of how agencies regulate through legislative rules. In other words, how do they structure their regulations, disaggregate regulatory obligations under the same statutory grant or aggregate them across multiple statutory provisions under the auspices of a single rule? This Part tackles some foundational issues. It first defines and operationalizes the concept of regulatory bundling. Then it presents a preliminary empirical overview of the phenomenon across agencies and across time. In doing so, it reveals historical trends in agency behavior and reflects on potential sources of heterogeneity.

\section{A. Concept and Measurement}

Regulatory bundling, at its core, refers to agencies' discretion to aggregate or disaggregate subjects during a single rulemaking. Put differently, agencies can make

\footnotetext{
${ }^{33}$ See, e.g., Arthur CeCil Pigou, The Economics of Welfare 132 (1938) (positing a public interest theory of regulation); George Stigler, The Theory of Economic Regulation, 2 BELL J. ECON. AND MGMT. SCI. 3 (1971) (developing an industry capture theory of regulation).
} 
many policy decisions in a rule or simply resolve one policy at a time. That discretion appears to be legislatively-blessed: the Administrative Procedure Act (APA) defines a "rule" as "the whole or a part of an agency statement of general or particular applicability and future effect." 34 While the legislative history is unilluminating, ${ }^{35}$ the text seems to anticipate that a rule can constitute either an entire agency statement of generality or just a portion of one. Rules, in other words, can resolve a set of subjects or simply component parts: whether the specification of a policy question, legal interpretation, enforcement scheme, or penalty structure, to name a few possibilities.

Even if the core concept of regulatory bundling is relatively straightforward, it raises difficult analytic and practical questions. Crisply delineating a "subject" or "issue" is notoriously challenging, as later discussed. ${ }^{36}$ So is deciding how to operationalize the degree of bundling observed: What is the best way to identify the extent to which an agency has "bundled"? One intuitive method might be to rely upon agencies' own descriptions of their rulemaking effort. Rules that are explicitly characterized as combinations of previous rules or that contain the term "omnibus" in the title might be one method. ${ }^{37}$ Agencies, however, are under no statutory requirement to label rules accordingly, so relying on this method is likely to yield inconsistent results. Agencies may also have incentives to characterize rules in ways that do not necessarily map onto any underlying substance. A behavioral definition is thus likely to be more meaningful.

Our measure of bundling derives from a subject list that agency officials are required to include in proposed and final rules. Since 1982, agencies must include a "list of subjects" in their rules, where the subjects derive from a set of standardized terms identified in a thesaurus known as the Federal Register Thesaurus of Indexing Terms. ${ }^{38}$ The requirement's stated purpose was to advance transparency and

\footnotetext{
${ }^{34} 5$ U.S.C. §551(4) (emphasis added). Some have written about the APA’s definition of a rule, but do not seem to have focused on the specific meaning of "whole or part." See, e.g., Sean Croston, It Means What It Says: Deciphering and Respecting the APA's Definition of "Rule", 53 WASHBURN L.J. 27 (2013); Ronald M. Levin, The Case for (Finally) Fixing the APA's Definition of "Rule, " 56 ADMIN. L. REV. 1077, 1083 (2004).

${ }^{35}$ By contrast, the Congressional and Senate Committee hearings and reports from the APA's legislative history focus on the evolution of the "general or particular applicability" provision, but neither the Federal Register Act nor the legislative history materials make any reference to the "whole or any part" language. See S. Rep. No. 813; H.R. Rep. No. 1497. The Final Report of the Attorney General's Committee on Administrative Procedure, issued in 1941, was based on extensive research into contemporary practices of federal administrative agencies and provided much of the framework for the ultimate product. While the Final Report focuses on agencies' procedures for rule-making, it never addresses the definition of a rule itself. See Final Report of the Attorney General's Committee on Administrative Procedure, Sen. Doc. No. 8, 77th Cong., 1st Sess. (1941).

${ }^{36}$ See infra Part III.B.1.

${ }^{37} \mathrm{Cf}$. KRUTZ, supra note 24 at 45 (considering defining "omnibus bill" by reference to the name of the bill, but rejecting method).

${ }^{38}$ Identification of Subjects in Agency Regulations (Final Rule), 46 Fed. Reg. $7162-01$ (Jan. 21, 1981). As background, the Office of the Federal Register (OFR) had first proposed the creation of a thesaurus four years earlier as part of a broader effort to facilitate regulatory monitoring. See Thesaurus of Indexing Terms, 42 FR 12986-01 (March 7, 1977). Its initial draft drew upon terms previously used in indices of the Federal Register and Code of Federal Regulations. Id. ("The subject
} 
encourage public participation. ${ }^{39}$ The hope was that interested parties could easily find regulations of concern. ${ }^{40}$ The citizen with "a buzzing seatbelt," for example, would not have to waste time searching indices for "cars," "automobiles" and "motor vehicles" but could instead focus on a single standardized term. ${ }^{41}$ The effort would also help the government consistently index other publications such as the Federal Register and Code of Federal Regulations. ${ }^{42}$ Supporters presciently noted that these standardized thesaurus terms could facilitate research and form the basis of a computer database in the future. ${ }^{43}$

For the past few decades, all proposed and final rules thus contain a list of subjects keyed to a fairly consistent standardized governmental thesaurus. We, in turn, collect the subjects listed as a metric of the extent to which a given rule is "bundled." The more subjects the rule lists from the thesaurus the more issues are bundled into the rule. To illustrate, consider the EPA's Clean Power Plan final rule issued under the Obama Administration, but now subject to repeal. ${ }^{44}$ The final rule listed the following subjects: Environmental protection; Administrative practice and procedure; Air pollution control; Intergovernmental relations; and Reporting and

terms included in this thesaurus were derived from terms previously used in Federal Register and Code of Federal Regulations indexes."). The Office then consolidated and cross-referenced the terms against other published thesauruses and indices. Id. (describing how proposed "terms were reviewed and consolidated and a cross-reference structure showing the relationships between terms was added" after which "[v]arious published thesauruses and indexes were consulted in selecting terms and crossreferences"). The result was a preliminary version published for public comment. Id. The more final version was then published in 1981 as a "dynamic document" that "could change through use." See Federal Register Thesaurus of Indexing Terms, 46 Fed. Reg. 12,618 (Feb. 17, 1981).

In practice, however, revisions have been fairly limited. In 1983, the Office added twenty-four new terms based on its two years of experience with the thesaurus. Some of these terms were used as indexing terms while others were added as cross-references. See Federal Register Thesaurus of Indexing Terms, 48 Fed. Reg. 27,646 (June 16, 1983). Seven years later, the Office similarly added twelve more terms based on suggestions from agencies and staff. Federal Register Thesaurus of Indexing Terms, 55 Fed. Reg. 38,444 (Sept. 18, 1990). Since then, OFR has added or revised terms on the order of two to three minor changes a quarter, with a more general organizational (as opposed to substantive) revision in 2016. See Telephone interview with Amy Bunk, Director of Legal Affairs and Policy for the Office of the Federal Register, National Archives and Records Administration (Feb. 2, 2018); Telephone interview with Brian Swidal, Senior Editor, Office of the Federal Register, National Archives and Records Administration (April 5, 2018).

${ }^{39}$ Identification of Subjects in Agency Regulations (Final Rule), 46 Fed. Reg. 7162-01 (Jan. 21, 1981) (invoking the "public's right to know about and participate in their Government and its day-to-day activities").

${ }^{40} I d$. (seeking to "provide a framework for information retrieval in the Federal Register system").

${ }^{41}$ See Standardization of Indexing Terms, Request for Individual and Agency Participation, 39 FR 14548, 14549 (April 24, 1974).

42 Identification of Subjects in Agency Regulations, 46 FR 7162-01 ("The identifying terms provided by the agencies with their regulations will be used at the OFR to expand the existing indexes to both the Federal Register and the Code of Federal Regulations.")

4346 Fed. Reg. 7162-01 ("The use of a controlled vocabulary, a thesaurus, is intended to improve research .... Through the use of automated technology the identifying terms will also be incorporated with the CFR text in a computerized data base for eventual automated information retrieval.)

${ }^{44} \mathrm{https}$ //www.epa.gov/stationary-sources-air-pollution/electric-utility-generating-units-repealingclean-power-plan 
recordkeeping requirements. Based on this list, our bundling measure would record a value of five: the agency listed five qualitative subjects.

This measure captures the number of issues addressed in a rulemaking based on the expert judgment of agency officials themselves. A major strength of this approach is that it relies on human coding by reference to a standardized and relatively uniform codebook (the thesaurus) - an approach often referred to as the "gold standard" in social science research. ${ }^{45}$ Human, as opposed to computerautomated coding, allows for the judgment and context necessary when parsing language. ${ }^{46}$ By contrast, alternative approaches such as topic-modeling, which attempts to classify the "topics" in a natural language corpus using algorithms, ${ }^{47}$ are widely considered second-best solutions when the resource costs required for human-coding are prohibitive. ${ }^{48}$

To be sure, it is possible for humans to be strategic about the measure in ways that automated approaches would not be. The Office of Federal Register (OFR), however, generally reviews agency submissions, albeit in an "advisory" manner and with a "light touch." 49 While the review does not focus heavily on the subject list, ${ }^{50}$ the threat of oversight may nevertheless help mitigate the possibility. OFR and its agency liaisons, who are responsible within the agency for Federal Register publications, are also repeat players. ${ }^{51}$ Thus, agency failures to comply may result in reputational sanctions and relational costs. Moreover, if officials were behaving strategically, we would observe behavioral changes around sharp transitions in the political or legal environment, in ways not evident in potentially less manipulable measures of bundling behavior, such as the number of Code of

\footnotetext{
45 See Paul DiMaggio, Adapting Computational Text Analysis to Social Science (and Vice Versa), 2015 BIG DATA \& SOC'Y 1 (2015) (noting that "human reasoning is routinely described as a 'gold standard' against which algorithmic output should be judged"); Laura Nelson, et al, The Future of Coding: A Comparison of Hand-Coding and Three Types of Computer-Assisted Text Analysis Methods (observing that "[m]ost social scientists continue to rely on traditional human coding methods as the gold standard for the analysis of such phenomena”). See also Justin Grimmer \& B. M. Stewart, Text as Data: The Promise and Pitfalls of Automatic Content Analysis Methods for Political Texts, 21 POLITICAL ANALYSIS 267 (2011) ("the complexity of language implies that automated content analysis methods will never replace careful and close reading of texts").

${ }^{46} \mathrm{Id}$. at 270 (acknowledging that "all automated methods are based on incorrect models of language" but that automation can usefully complement or supplement human coding)

${ }^{47}$ For the seminal piece on this topic, see David M. Blei et al., Latent Dirichlet Allocation, 3 J.

MACHINE LEARNING RES. 993 (2003).

${ }^{48}$ See sources cited supra note 45.

${ }^{49}$ Swidal interview, supra note 38; Bunk interview, supra note 38.

${ }^{50} \mathrm{Id}$. See also Swidal interview, supra note 38.

${ }^{51}$ Office of the Federal Register, 2015 Federal Register Conference, https://www.federalregister.gov/reader-aids/office-of-the-federal-register-blog/2015/06/2015-federalregister-liaison-conference ("Each federal agency is required to designate an individual as a point of contact for all documents their agency publishes in the Federal Register.").
} 
Federal Regulation Parts to which the rule corresponds. ${ }^{52}$ The appendix investigates strategic manipulation but finds little evidence to support that possibility. ${ }^{53}$

Our thesaurus-based measure may be criticized in other ways as well. For instance, the measure could double count the number of issues when officials list both "general" and "specific" terms. "54 "Air transportation" and "air taxis" both appear in the thesaurus, for example, so a rule relating to air taxis could list both subjects. It is also possible that the thesaurus is not specific enough in some areas, and that multiple "issues" could appear under one general heading. Instead of double-counting, perhaps the thesaurus is not granular enough. We address some of these concerns in the appendix, by creating an "adjusted" measure that accounts for the presence of both specific and general terms for a rule. We are able to do so based on the thesaurus itself, which notates when terms may be more specific than others. ${ }^{55}$ Importantly, we find that none of our results change qualitatively with this adjusted measure.

Finally, yet another concern may be intercoder reliability, the extent to which independent coders at different agencies evaluate the content of interest and reach the same conclusion. Ensuring consistency between dozens of agencies with varying staff capacities is undoubtedly a difficult task. ${ }^{56}$ These concerns, however, are mitigated by the fact that agency rulewriters are provided coding guidance in a document drafting handbook published by the Office of Federal Register. ${ }^{57}$ The handbook applies to all documents, including rules, published in the Federal Register. ${ }^{58}$ Specifically, the handbook encourages rule-writers to choose standardized terms based on the Code of Federal Regulation (CFR) Part affected by the regulation. The handbook then directs readers to thesaurus' website, which contains a link to the indexing terms associated with each CFR Part. ${ }^{59}$ In this manner, the guidance encourages interagency consistency by providing a standardized list of terms with which to begin based on how the regulation will eventually be codified.

Further providing some confidence in the measure, it correlates in sensible ways with other possible indicia of the extent to which a rule bundles issues. For instance, one might expect agencies to refer to more CFR parts or subparts in a bundled rule; likewise, one might expect bundled rules to take longer to explain. These indicia are imperfect measures of bundling in a number of ways. A CFR Part,

${ }^{52}$ Note that we do not adopt these other measures because they are cruder and are likely to sensitive to differences over time and across agencies in how the CFR itself is structured. However, at least in narrow windows of time, the number of CFR Parts that a rule addresses provides a plausible check on whether agency officials act strategically with respect to the number of subjects they list.

${ }^{53}$ See Appendix.

${ }^{54}$ See Swidal interview, supra note 38 (acknowledging potential overlap between general and specific terms).

${ }^{55}$ Email from Brian Swidal, Senior Editor, Office of Federal Register, National Archives and Records Administration to authors (May 2, 2018).

${ }^{56}$ See Swidal interview, supra note 38 (describing different coding practices at different agencies).

${ }^{57}$ https://www.archives.gov/files/federal-register/write/handbook/ddh.pdf

${ }^{58} \mathrm{Id}$.

${ }^{59}$ https://www.archives.gov/federal-register/cfr/subjects.html. See Telephone interview with Andrew Emery, President of The Regulatory Group (April 10, 2018). 
for example, often contains many subsidiary issues and is therefore a very coarse indicator of bundling. The number of words in the rulemaking document, likewise, reflects a wide variety of forces, only one of which is the extent to which the rule bundles various issues. Nevertheless, one would expect positive correlations between the number of subjects listed and these indicia. In fact, all of these indicia correlate positively (albeit weakly) with the measure of bundling in our dataset, suggesting its validity. The correlation between our measure and the log number of CFR parts is 0.07 , between the number of sub-parts is 0.17 , and between the number of words in the rulemaking document 0.26 .

As for the dataset of underlying rules, the entries derive from the Federal Register between 2000 and 2017, almost twenty years of rulemaking data. The Appendix provides more detail, ${ }^{60}$ but agencies are legally required to publish their final rules in the Federal Register, unless providing actual or personal service on potentially affected parties. ${ }^{61}$ Thus, these data are likely the most complete look possible at the universe of proposed and final rulemakings. Earlier efforts to study agency behavior, by contrast, have relied almost exclusively on Unified Agenda entries to capture rulemaking behavior. ${ }^{62}$ Most users, however, have acknowledged that these data are incomplete. ${ }^{63}$ Overall, our dataset includes approximately 19,000

${ }^{60}$ For a more detailed discussion of the dataset, see also Jennifer Nou \& Edward H. Stiglitz, Strategic Rulemaking Disclosure, 88 S. CAL. L. REV. 733 (2016).

615 U.S.C. § 553(b) (2000) ("General notice of proposed rule making shall be published in the Federal Register, unless persons subject thereto are named and either personally served or otherwise have actual notice thereof in accordance with law."). 62. See, e.g., Edward H. Stiglitz, Unaccountable Midnight Rulemaking? A Normatively Informative Assessment, 17 N.Y.U. J. LeGIS. \& PUB. POL’Y 137, 156 (2014); Steven J. Balla, Political Control, Bureaucratic Discretion, and Public Commenting on Agency Regulations, 93 PUB. ADMIN. 524, 536 n.12 (2014); Jack M. Beermann, Midnight Rules: A Reform Agenda, 2 MicH. J. ENVTL. \& ADMIN. L. 285, 319 (2013); Alex Acs \& Charles M. Cameron, Does White House Regulatory Review Produce a Chilling Effect and "OIRA Avoidance" in the Agencies, 43 PRESIDENTIAL STUD. Q. 443, 443 (2013); Susan Webb Yackee, The Politics of Ex Parte Lobbying: Pre-proposal Agenda Building and Blocking During Agency Rulemaking, 22 J. PUB. ADMIN. RES. \& THEORY 373, 379 (2012); Jason Webb Yackee \& Susan Webb Yackee, Divided Government and US Federal Rulemaking, 3 REG. \& Gov. 128 (2009); Stephen M. Johnson, Ossification's Demise? An Empirical Analysis of EPA Rulemaking from 20012005, 38 ENVTL. L. 767, 780-81 (2008); Stuart Shapiro, Presidents and Process: A Comparison of the Regulatory Process Under the Clinton and Bush (43) Administrations, 23 J.L. \& POL. 393, 400-01 (2007); Michael R. See, Willful Blindness: Federal Agencies' Failure to Comply with the Regulatory Flexibility Act's Periodic Review Requirement-And Current Proposals to Invigorate the Act, 33 FORDHAM URB. L.J. 1199, 1217-19 (2006); Jason Webb Yackee \& Susan Webb Yackee, Administrative Procedures and Bureaucratic Performance: Is Federal Rule-making "Ossified"?, 20 J. PUB. ADMIN. RES. \& THEORY 261, 267-68 (2006); Jason M. Loring \& Liam R. Roth, After Midnight: The Durability of the Midnight Regulations Passed by the Two Previous Outgoing Administrations, 40 WAKE FOREST L. REv. 1441, 1454-55 (2005); Steven J. Balla, Between Commenting and Negotiation: The Contours of Public Participation in Agency Rulemaking, 1 I/S: J.L. \& POL'Y FOR INFO. SOC'Y 59, 70 (2005) (" $[\mathrm{U}] \mathrm{se}$ of the Unified Agenda ensures that the set of rulemakings under study represents as complete a snapshot as possible of [Department of Transportation rulemaking activities] . . .."); Steven J. Balla \& John R. Wright, Consensual Rule Making and the Time It Takes to Develop Rules, in POLITICS, PoLICY, AND ORganizATIONS 187-206 (George A. Krause \& Kenneth J. Meier eds., 2003); Steven J. Groseclose, Reinventing the Regulatory Agenda: Conclusions from an Empirical Study of EPA's Clean Air Act Rulemaking Progress Projections, 53 MD. L. REV. 521 (1994).

63. See, e.g., Jerry L. Mashaw, Improving the Environment of Agency Rulemaking: An Essay on Management, Games, and Accountability, 57 L. CONTEMP. PROBS. 185, 198 n.41 (Spring 1994) (noting that his investigation into the quality of the Unified Agenda data was "sufficiently disappointing that [he did] not pursue[] the analysis on a more 'scientific' basis"); O'Connell, supra note 28, at 927 n. 108 (2008) ("[The] Unified Agenda data are not perfect; they need confirmatory research."). 
proposed rules and 41,000 final rules. ${ }^{64}$ In addition to the listed subjects, we collect the full text of the proposed and final rules, as well as multiple other variables of interest, such as the identity of the issuing agency, the date of publication, and the length of the rule.

\section{B. Trends}

Administrative agencies appear to be increasingly bundling subjects in their rulemakings. As Figure 1 below illustrates, the average number of subjects has been more or less steadily increasing during the last twenty years for both proposed (left panel) and final rules (right panel). ${ }^{65}$ Each dot represents the average number of subjects listed by agencies in proposed or final rules in a given month; the grey line shows the trend over time. The trend is more marked for proposed rules. For the first 24 months of our series, the average proposed rule contained roughly 4.03 listed subjects; in the final 24 months of our series, it contained an average of approximately 4.8 listed subjects. While the absolute magnitude (less than one subject over the time period) should not be overstated, it does represent an increase of about 19 percent, averaged across thousands of rules. The number of listed subjects in final rules has also increased, but more gradually. For final rules, the average number of listed subjects increased from about 4.4 in the opening 24 months to about 4.9 in the closing 24 months, an increase of about 10 percent.

On the one hand, this observation could reflect a broader phenomenon: policymaking instruments across a variety of settings have become longer and more complex over time. Both statutes and Supreme Court judicial opinions, for example, reflect this dynamic. ${ }^{66}$ Specific explanations vary, but likely reflect related causes. The economic and social conditions that the law seeks to regulate, for example, have become more interdependent and uncertain over time. ${ }^{67}$ Consumers of the law -

\footnotetext{
${ }^{64}$ In earlier research, we find that final rules dramatically outnumber proposed rules. See Nou \& Stiglitz, supra note 63.

${ }^{65}$ Specifically, we create monthly bins of rules and calculate the average number of subjects in each bin. The left panel of the figure presents the results for proposed rules; the right panel, final rules. Within each panel, time runs on the $\mathrm{x}$-axis and the indicated measure runs on the $\mathrm{y}$-axis; the vertical dashed lines represent shifts in administrations; each dot represents the average for the relevant metric in a month, and the line shows the trends over time. The trend line is produced using a locally weighted average of the years, so that at any point the line represents the average proportion, with years closer to that point weighted more heavily than years farther from that point.

${ }^{66}$ See, e.g., Michael James Bommarito II \& Daniel Martin Katz, A Mathematical Approach to the Study of the United States Code, 389 Physica A (2010), available at http://papers.ssrn.com/sol3/papers.cfm?abstract_id=1578094 (finding that the "Code has grown in its amount of structure, interdependence and language"); Adam Liptak, Justices Are Long on Words but Short on Guidance, N.Y. TIMES (Nov. 17, 2010) (reporting that the "number of words per decision has been climbing"), available at http://www.nytimes.com/2010/11/18/us/18rulings.html?_r=0 ${ }^{67}$ See Peter H. Schuck, Legal Complexity: Some Causes, Consequences, and Cures, 42 DUKE L. J. 1, 25 (1992).
} 
from lawyers, to judges, to the public - now also have greater access to sophisticated legal technology. ${ }^{68}$ Producers of the law also now have larger staffs, including legislative assistants and law clerks, who demonstrate their value by contributing to the length and sophistication of statutes and legal reasons. For all these reasons, legal instruments as a whole often address more subjects.

Figure 1: Bundling Activity Trends: 2000-17
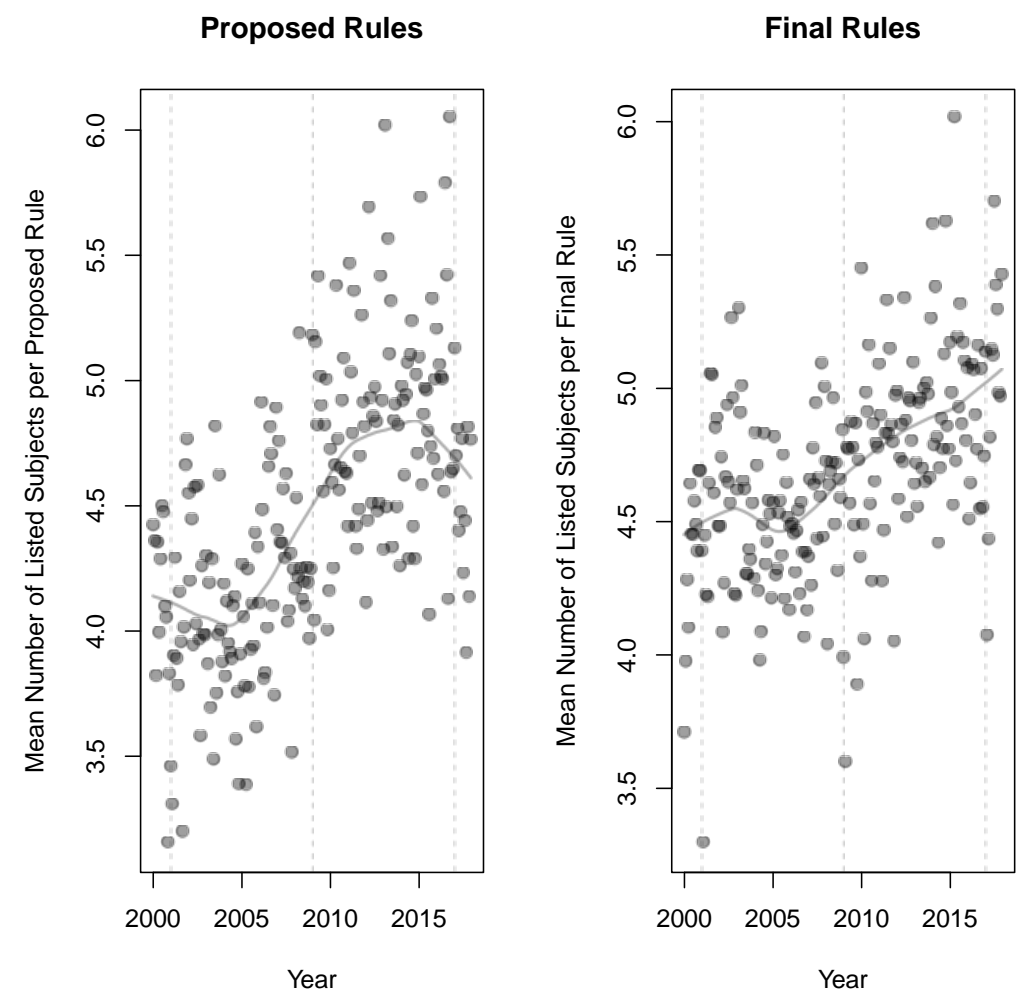

Administrative agencies may likewise engage in more bundling due to a number of related developments in the regulatory state. A new rule today is likely to touch on several existing rules or implicate a number of overlapping statutes. ${ }^{69} \mathrm{New}$ regulations are written against the backdrop of an increasing store of existing legal obligations, requiring more topics to be addressed for seemingly simple changes. This contrasts with the earlier days of the administrative state, when agencies developed novel regulatory programs in more clearly delineated fields. Congress, too, has increasingly delegated policy issues to multiple agencies, compelling

${ }^{68} I d$.

${ }^{69}$ See Robert B. Ahdieh, Dialectical Regulation, 38 ConN. L. REV. 863 (2006) (noting that with regulatory "growth has come a concomitant increase in the engagement of regulatory institutions across jurisdictional lines") 
agencies to write joint rules dealing with a greater number of topics. ${ }^{70}$ As more agencies become involved, they may spot a greater number of issues implicated. The increase may also be explained as a behavioral reaction to political and judicial oversight or greater litigation threats from those involved in the public comment process. Perhaps bundling becomes the favored strategy for overwhelming resourceconstrained opponents.

To begin to shed light on these various dynamics, note that some agencies bundle more than others. Specifically, Figure 2 below shows that several agencies such as the Environmental Protection Agency (EPA), the Department of Housing and Urban Development (HUD), and the Department of Veterans Affairs (VA) issue a larger number of bundled rules on average. (The appendix contains the full list of agency abbreviations.) By contrast, the Departments of Defense (DOD) and Commerce tend not to issue proposed or final rules with many listed subjects - on average, they list fewer than two subjects per proposed or final rule. This interagency variation may reflect many differences worthy of further exploration.

EPA and HUD, for example, operate under different enabling statutes that may address many more issues than a more single-mission agency like DOD. They may therefore have the ability to bundle in ways that DOD does not. In other words, Congress itself may constrain agency bundling choices when it makes choices about agency jurisdiction. Alternatively, EPA, HUD, and VA may also be more heavily monitored, thus inducing more bundling in attempts to divide and distract the attention of resource-constrained interest groups or to placate the various stakeholders in play. These agencies, as a group, receive more public attention than the General Services Administration (GSA). In addition, the trends may also reflect changes in underlying rulemaking behavior outside of bundling and splitting incentives. Put differently, there may be differences in the composition of underlying rules, which are difficult to isolate, but important to recognize. ${ }^{71}$

\footnotetext{
${ }^{70}$ See, e.g., Jacob E. Gersen, Overlapping and Underlapping Jurisdiction in Administrative Law, 2006 SuP. CT. REV. 201 (2006); Jody Freeman \& Jim Rossi, Agency Coordination in Shared Regulatory Space, 125 HARV. L. REV. 1131 (2012).

71 Suppose, for instance, that the VA issued few rules at the start of the series and many in the end of the series. Overall, this would produce an upward trend in bundling over time, but possibly due solely to the greater activity of the VA. To account for this, it is of interest to decompose the increase into compositional and secular factors. In particular, one can remove compositional changes, as in the VA example, by fixing the composition at the values of the first year in the series. Say, for instance, that the VA issued 5 percent of the rules in 2000. Then, going forward, we weight the average subjects listed by the VA as though the VA issued five percent of the rules in later periods, even if in fact the VA issued ten or fifteen percent of the rules in those periods. This resembles the approach taken, e.g., in Olivier Bargain \& Tim Callan, Analyzing the Effects of Tax-Benefit Reforms on Income Distribution: A Decomposition Approach, 8 J. ECON. INEQUALITY 1 (2010); Olivier Bargain et al, Tax Policy and Income Inequality in the U.S., 1978-2009: A Decomposition Approach, 53 ECON. INQUIRY 1061 (2015).

This analysis suggests that about half of the increase appears to owe to compositional changes. For instance, as reported above, the number of subjects increased by about 19 percent between the first 24 and the last 24 months of the series. With the composition fixed, the increase reduces to about 11 percent for NPRMs. Along the same lines, for final rules, the unadjusted increase between the first and last 24 months is about 10 percent. With the agency composition fixed, the increase is only about 5 percent using the same periods of comparison. The problem with this
} 


\section{Figure 2: Bundling at the Agency Level}

\section{Proposed Rules}

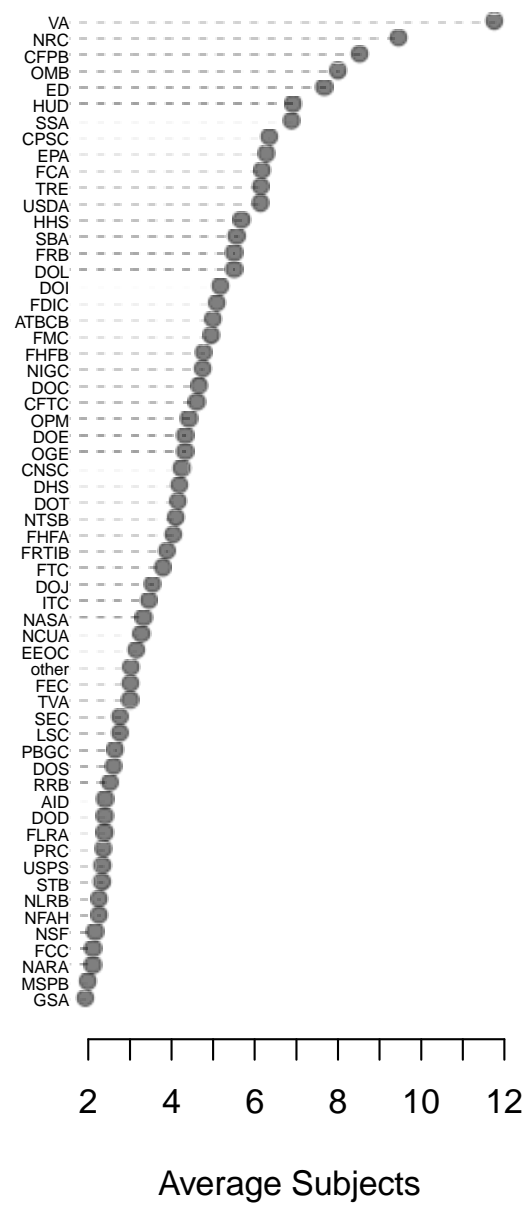

Final Rules

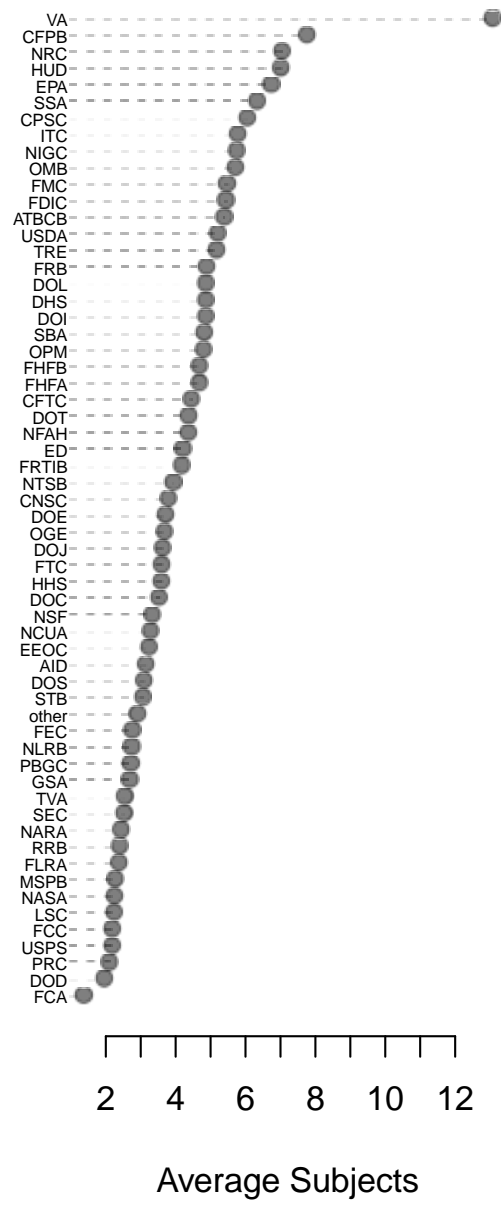

Less substantively, it is also possible that there are simply coding discrepancies across administrative agencies. Perhaps coding practices at VA differ systematically than those at the Farm Credit Administration. Finally, the drafters of the Thesaurus may also have split subject areas in ways that are reflected in the results, but do not necessarily correspond to behavioral choices made by particular agencies.

More generally, the bundling behavior of an agency is broadly similar for proposed and final rules. If an agency tends to bundle on proposed rules, that is, it also tends to do so for final rules. Across agencies, the correlation between the number of listed subjects in proposed and final rules is 0.84 . Figure 3 below plots the average number of subjects for final rules against the average number of subjects for

approach, however, is that these compositional changes are themselves endogenous to the bundling and splitting dynamics we examine. Isolating them is thus not a straightforward task. 
proposed rules. The dashed line on a 45-degree angle represents the line of perfect correspondence, such that an agency that falls on the line has the same number of subjects in its proposed and final rules. Agencies above the line tend to have more subjects in final than proposed rules; and agencies below the line tend to have fewer subjects in final than proposed rules. We later examine how the number of subjects evolves within a rulemaking effort from proposed to final rule.

Figure 3: Bundling in Proposed and Final Rules, by Agency

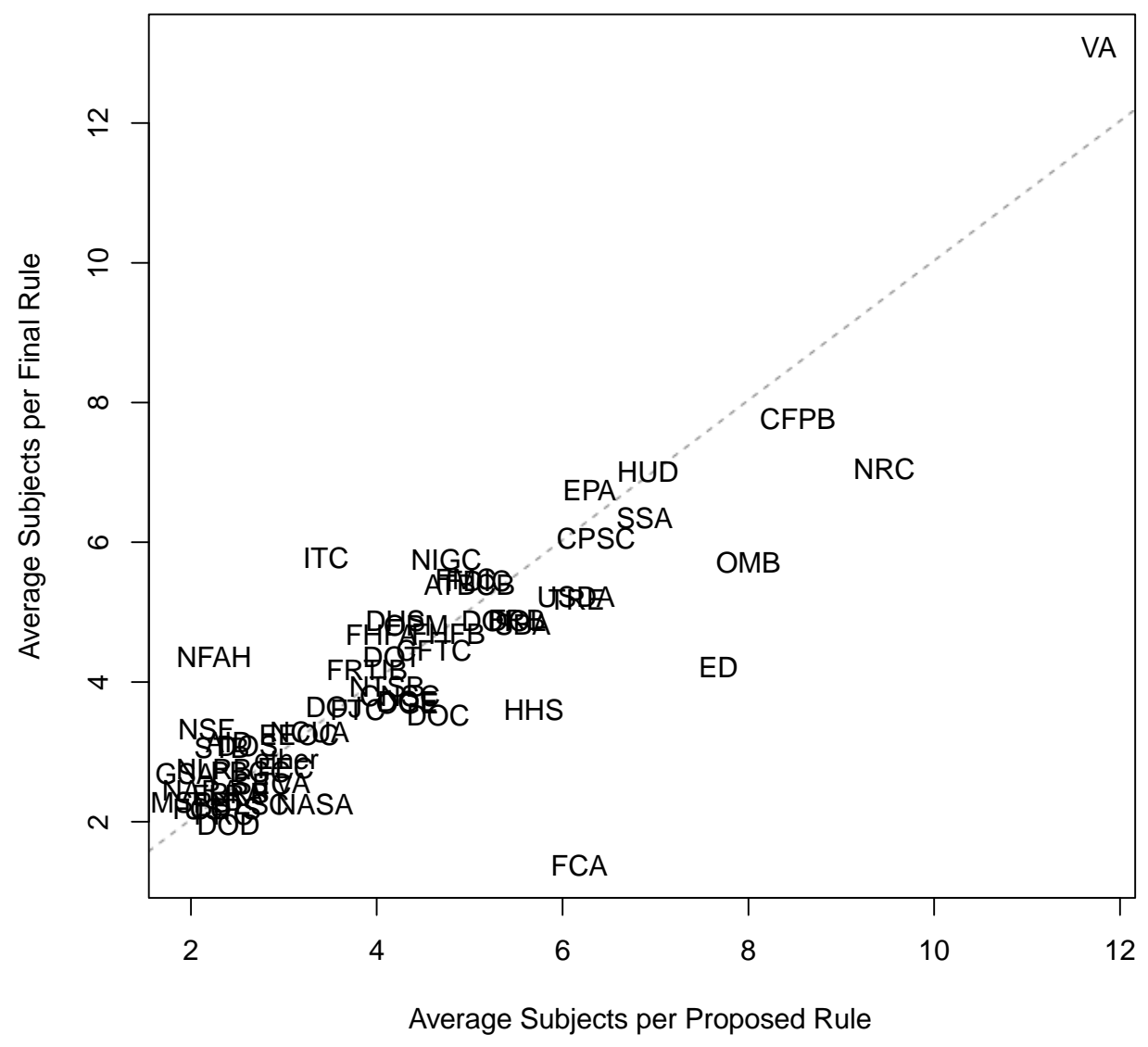

II. Bundlers and Splitters

Given this initial snapshot, this Part now considers in more detail the incentives agencies have to bundle and split rules at a given point in time. The first section examines factors influencing the agency's decision-making independent of external oversight, while the second introduces the dynamics created by political and 
judicial monitors. These dimensions, of course, are linked, ${ }^{72}$ but considering each in isolation is useful.

\section{A. Internal Regulatory Drafters}

\section{Intra-agency bargaining}

Like legislatures drafting statutes, agencies drafting rules require the agreement of multiple internal actors. This dynamic is especially true in multimember commissions, which normally require a majority vote to approve a rule. ${ }^{73}$ But even in single-headed agencies, regulatory drafting involves many internal constituencies with conflicting points of view. ${ }^{74}$ Career staff in the relevant program office approach the rule with their subject-matter expertise. ${ }^{75}$ Lawyers from the general counsel's office bring their legal perspectives. ${ }^{76}$ Policy analysts or economists may press cost-benefit or other decision-making frameworks. ${ }^{77}$ All are usually involved in the first stages of regulatory drafting, during which they will determine the initial scope of the regulation. These rule-writing teams will usually decide which provisions the regulations should contain as a preliminary matter. Of course, agency management can also determine the initial scope of a rule when composing these teams in the first place. ${ }^{78}$

Regulatory bundling facilitates negotiations between these different internal groups. Say a policy analyst, for example, determines that a regulation dealing with issue A interferes with her objectives on some other issue, issue B. The program officer who is coordinating the rule may offer to include provisions relating to issue B to secure the cooperation of the policy analyst. This scenario would result in an increase in bundling due to internal politicking at the agency. Alternatively, a lawyer may conclude that a particular part of the rule is subject to a statutory deadline and therefore must be expedited. She might thus convince the team to split off that piece from the rest of the rule, which has a slower timetable. This give-and-take will likely continue until a consensus has been reached.

\footnotetext{
${ }^{72}$ Cf. Gillian E. Metzger, The Interdependent Relationship Between Internal and External Separation of Powers, 59 EMORY L.J. 423 (2009)

${ }^{73}$ See Bradley C. Canon, Voting Behavior on the FCC, 13 MidwEST J. POL. SCI. 587 (1969).

${ }^{74}$ See Wesley A. Magat, Alan. J. Krupnick, Winston Harrington, Rules IN THE MaKing 74 (1986) (describing "conflict between the drafters of the rule and the economic analysis group"); Elizabeth Magill \& Adrian Vermeule, Allocating Power Within Agencies, 120 YALE L.J. 1032, 1072 (2011).

${ }^{75}$ Fed. Highway Admin., Rulemaking Manual 7 (2000) [hereinafter FHWA ManUal], http://www.dot.gov/sites/dot.dev/files/docs/FHWARulemaking\%20Manual.pdf (identifying the "program office" as the "technical office responsible" for "[d]rafting rulemaking documents").

${ }^{76}$ Magill \& Vermeule, supra note 74.

${ }^{77} \mathrm{Id}$.

${ }^{78}$ See Emery interview, supra note 59.
} 
From there, the draft rule will then undergo an agency-specific clearance procedure involving review by others in the agency, as well as up the hierarchy to political appointees. ${ }^{79}$ At this point, many other offices are likely to be involved. Rule drafters within the Internal Revenue Service (IRS) must secure the approval of a branch reviewer; the Associate, Deputy, and Chief Counsels; the Assistant to the Commissioner; and, finally, the Commissioner before moving on to the Department of Treasury for final authorization. ${ }^{80}$ The Federal Highway Administration requires concurrence from the agency's other program offices, then its legal division, its Legislation and Regulations Division, and, finally, the agency's chief counsel. ${ }^{81}$ Generally speaking, those in these clearance chains do not possess hard internal vetoes in the sense that they can unilaterally stop the rulemaking from proceeding. ${ }^{82}$ However, they can delay the draft rules by raising objections during the sign-off process. ${ }^{83}$

As a result, rule-writing teams may bundle or split rules to mollify the actual or anticipated resistance faced within the agency. If a team within IRS, for example, expects that a specific provision will ultimately be rejected by a newly-appointed Chief Counsel, it can split off that provision for a future rulemaking - perhaps when a more sympathetic Chief Counsel has been appointed. Splitting controversial provisions can help ensure that regulatory efforts are not sunk by skittish agency heads. ${ }^{84}$ At the same time, drafters may also bundle a large number of regulatory provisions together in the hopes that more controversial provisions duck under the radar. In other words, bundling can allow what amount to regulatory riders: provisions that are only tenuously related to the rule, but nevertheless attached in order to facilitate passage. ${ }^{85}$

Should disagreements amongst these offices nevertheless persist, clearance procedures also specify how these issues should be elevated up the agency hierarchy and which higher-level policy official should ultimately resolve the dispute. ${ }^{86}$ At the EPA for instance, the Deputy Administrator has been designated to

\footnotetext{
${ }^{79}$ See Jennifer Nou, Intra-Agency Coordination, 129 HARV. L. REV. 421, 468 (2015) (discussing internal clearance procedures).

${ }^{80}$ See IRS, INTERNAL REVENUE MANUAL $\$$ 32.1.6.8.4, http://www.irs.gov/irm/part32/irm _32-001-006.html [http://perma.cc/78GX-GPUN].

${ }^{81}$ See FHWA MANUAL, supra note 75 , at 7.

${ }^{82}$ See Margo Schlanger, Offices of Goodness: Influence Without Authority in Federal Agencies, 36 CARDOZO L. REV. 53, 94 (2014) (“[O]ne government office ordinarily cannot authoritatively stop the issuance of a document by its sibling office.").

${ }^{83} I d$. ("[I]t is possible to give an office assigned a clearance role something very close to that power, by structuring the conflict resolution procedure so that it is the operational office that needs to 'appeal' a clearance denial.").

${ }^{84}$ See Emery interview, supra note 59.

${ }^{85} \mathrm{Id}$.

${ }^{86}$ The FHWA manual, for instance, explicitly states that the rulemaking team is responsible for "resolv[ing] issues or elevat[ing] issues to management for resolution." FHWA MANUAL, supra note 50, at 8. Similarly, the EPA provides that "[i]f workgroup members cannot agree, the issues of disagreement should be presented to management for resolution." See ENVIRONMENTAL Protection Agency, EPA's ACtion DEVElopment Process 34 (2011) [hereinafter EPA's ACTION DEVELOPMENT PROCESS],
} 
adjudicate the disagreement, ${ }^{87}$ though she allows for elevation to the Administrator for the most controversial issues. ${ }^{88}$ By comparison, the Commissioner of the IRS specifies that the Associate Chief Counsel within a division should usually resolve the dispute, though the matter could also be elevated to higher levels when necessary. ${ }^{89}$ Indeed, in most agencies, the ultimate authority to bundle or split a rule lies with the statutorily designated political appointee, usually the head of the agency.

The dynamics become even more complicated when there are several agency heads involved - as in joint rulemakings or on multimember boards and commissions like the Securities and Exchange Commission or the National Labor Relations Board. ${ }^{90}$ Individual commissioners and board members often arrive in staggered terms, appointed by different Presidents, and sometimes as a result of party balancing requirements. ${ }^{91}$ Unsurprisingly, they approach their jobs from different backgrounds, career experiences, and priorities. ${ }^{92}$ Consequently, these agency heads often desire different regulatory outcomes even when nominally members of the same political party. ${ }^{93}$ In these situations, they can strike compromises through bundled rules by exchanging certain favored provisions for less favored ones. ${ }^{94}$ The strategy becomes particularly attractive when the agency is unlikely to engage in further rulemaking on a particular topic due to political constraints; under these circumstances, there is more pressure to resolve disagreements within the context of a single rule.

In this manner, regulatory bundling may be explained by internal negotiations within an agency drafting the rule. Diverse agency constituencies, including programmatic career staff, policy analysts, and lawyers can engage in bargaining

http://yosemite.epa.gov/sab\%5CSABPRODUCT.NSF/5088B3878A90053E8525788E005EC8D8/\$Fil e/adp03-00-11.pdf; see id. at 71 (discussing the process of informal and formal elevation of disagreements to management and other policy officials such as the Administrator).

${ }^{87}$ See William F. Pedersen, Jr., Formal Records and Informal Rulemaking, 85 YALE L.J. 38, 57 (1975) ("By the nature of the way EPA is (dis)organized, really sticky issues are escalated at least to the [Deputy Assistant Administrator] level and maybe higher for resolution." (alteration in original) (quoting Memorandum from a senior EPA official to William F. Pedersen, Jr. (May 4, 1975) (on file with Yale Law Journal))).

${ }^{88}$ See EPA's ACTION DEVELOPMENT Process, supra note 86, at 71 (noting that issues could ultimately be formally elevated to the Administrator, though doing so would be "unusual" except for the most significant rules).

${ }^{89}$ IRS, supra note $80, \S 32.1 .6 .3$.

${ }^{90}$ See generally MARSHALl J. BREGER \& GARY J. EDLES, INDEPENDENT AGENCIES IN THE UNITED STATES (2015).

${ }^{91}$ See Brian D. Feinstein \& Daniel J. Hemel, Partisan Balance with Bite, 118 CoLuM. L. REv. 9 (2018); Daniel E. Ho, Congressional Agency Control: The Impact of Statutory Partisan Requirements on Regulation 1-3 (Feb. 12, 2007) (unpublished manuscript).

${ }^{92}$ See BREGER \& EDLES, supra note 90.

${ }^{93}$ See Sharon Jacobs, Administrative Dissents, 59 WILLIAM \& MARY L. REV. 541 (2017).

${ }^{94}$ See Marshall J. Breger \& Gary J. Edles, Established by Practice: The Theory and Operation of Independent Federal Agencies, 52 ADMIN. L. REV. 1111, 1113 (2000) (independent agencies "are also multi-member organizations, a fact that tends toward accommodation of diverse or extreme views through the compromise inherent in the process of collegial decisionmaking") 
when deciding the scope of a rule. These negotiations can then further extend across agency offices as the rule undergoes a horizontal review process. From there, any remaining disagreements will be elevated up to political appointees who may further decide to add or split the subjects addressed in the rulemaking. When there are multiple agency heads, regulatory bundling allows for logrolling and negotiation to occur before rules are subject to a vote.

\section{Rule production costs}

Beyond internal agency compromises, the production costs of regulatory drafting may affect bundling behavior as well. In thinking about the resource burdens of writing a rule, it is helpful to distinguish between the fixed, variable and marginal costs. A fixed cost is any cost that does not vary with the number of subjects addressed in a rule. ${ }^{95}$ For instance, agencies that decide to engage in rulemaking must establish a docket, ${ }^{96}$ secure boilerplate templates, and draft other standardized language necessary to conform to the Federal Register Document Drafting Handbook. ${ }^{97}$ In addition, most agencies require internal management-related paperwork from rulewriting offices seeking permission to begin regulatory drafting. ${ }^{98}$ These documents often require an abstract of the contemplated regulation and supporting justification. ${ }^{99}$

The presence of fixed production costs generally encourages regulatory bundling. Bundling allows agencies to address more issues while paying the fixed costs only once. Bundling, that is, allows for greater administrative efficiency. Splitting the issues into separate rulemakings, by contrast, requires the agency to pay the fixed costs repeatedly. Holding all else equal, one would thus expect to see greater bundling to occur when the fixed costs of producing a rule increase. One would also expect the same result when an agency suffers budget cuts. Conversely, when fixed costs fall, agencies may be more inclined to split provisions into separate rules.

A variable cost, by contrast, is one that varies with the number of subjects addressed by a rule. Generally speaking, the more issues addressed in a regulation, the more costly the rule drafting effort. Some obvious variable costs include the resources necessary for researching additional technical issues or preparing the necessary analytical documents associated with more issues. In addition, there are also greater publication costs in the Federal Register, which currently charges a per

\footnotetext{
${ }^{95}$ There are some fixed costs that agencies must absorb even if they decide not to write any rules. These include, for example, rulewriting staff salaries and other normal agency operating costs. However, these costs would seem to go to the question of how many rules an agency produces, not the scope of those rules.

${ }^{96} \mathrm{https}: / / \mathrm{www}$.epa.gov/dockets/about-epa-dockets\#docket

${ }^{97}$ Emery interview, supra note 59.

${ }^{98}$ Id. See, e.g., EPA's ACTION DeVElopment PROCESS, supra note 86, at 14 ("Prior to initiating substantive development activities, the lead office prepares and submits a tiering form describing the new action.").

${ }^{99}$ See Emery interview, supra note 59.
} 
page rate ${ }^{100}$ Relatedly, marginal costs reflect the cost of adding the incremental subject to a rule. Importantly, marginal costs may be either increasing or decreasing: when marginal costs are increasing, each additional issue is more costly than the last; when decreasing, each additional issue, though still costly, is less costly than the previous one. Increasing marginal costs would tend to discourage agencies from issuing rules that touch on many subjects. Decreasing marginal costs, on the other hand, offer economies of scale and thus encourage bundling.

On the whole, the marginal costs of regulatory drafting are likely generally increasing, though they may initially decrease at some point. They may decrease when a rule-writing team gains the requisite expertise necessary to regulate (or deregulate) in a particular domain. Once a baseline level of knowledge has been obtained, the marginal subject addressed can be cheaper to resolve. On the other hand, at some point, the resources of the team present a bottleneck, when marginal costs begin to increase sharply. Each new additional issue the team must address becomes increasingly expensive as the rulewriters are required to work overtime or are taken away from other higher-priority matters. Because bundled regulations strain agency resources at the same time, this form of congestion can be challenging for agencies to accommodate and can lead to staffing shortages. Partitioning out the issues across separate rules, on the other hand, allows agencies to smooth out their workflows.

\section{B. Monitors}

While intra-agency dynamics can help to explain the scope of a rule, external monitors such as the President, Congress, and the courts also play an important role. These monitors can effectively veto rules, leading agencies to draft rules in their shadow. Put differently, strategic agencies can respond to the incentives created by executive and judicial review. The first section thus explores when and why agencies may bundle or split rules when confronted with oversight generally. The second section then examines the more particular dynamics presented by executive, legislative, and judicial monitors. It also addresses the ways in which these overseers can bundle and split rules unilaterally and the mechanisms they use to do so.

\section{Facing Oversight}

When confronted with a monitor than can reverse its policy decision, a strategic agency faces a set of tradeoffs in deciding whether to bundle or split the regulatory provisions it seeks to promulgate. Say that an agency can pack ten regulatory provisions into one rulemaking or else split them into ten separate

\footnotetext{
${ }^{100}$ Government Printing Office, Circular Letter No. 1003 (March 29, 2018), available at https://www.gpo.gov/how-to-work-with-us/agency/circular-letters/new-federal-register-publishingrates (lowering per page Federal Register Publication rates).
} 
rulemakings. What informs this choice when it comes to thwarting external review? Would a strategic agency prefer to bundle or split their rules?

Much of the answer depends on the structure of monitoring costs - how overseers must invest resources to observe an agency's rulemaking efforts before deciding to intervene. ${ }^{101}$ It is helpful, once again, to refer to marginal and fixed costs - now applied to the monitoring of a given rulemaking effort. Marginal monitoring costs are the costs associated with evaluating the incremental subject in a rule. Fixed monitoring costs are those that do not vary with the scope of a rule. Say it costs a flat fee just to access each Federal Register entry. Those fees would constitute a fixed monitoring cost.

If the marginal costs of monitoring issues are increasing, strategic agencies may be able to overwhelm overseers more effectively by bundling rather than splitting. Bundling makes it more expensive for monitors to review because each additional subject in a rule is increasingly costly to evaluate, which may lead resource-constrained agencies to skim over some provisions. As a result, the most contentious provisions are likely to gain more attention, thus allowing less contentious ones to fly under the radar. In this scenario, bundling serves to insulate some issues from review and reversal. Thus, under increasing marginal costs, one would expect agencies to engage in more bundling. Conversely, with decreasing marginal costs, one would expect less bundling.

As an independent matter, when the fixed costs to monitoring are positive and material, splitting rules is likely to be more effective than bundling in thwarting oversight. Ten separate rules will deplete a greater number of monitoring resources than one bundled one since monitors will have to incur set costs to evaluate each rule. So, as fixed monitoring costs increase, a strategic agency would often do better to split their provisions across rules to drain the resources of their overseers, thus reducing oversight and opposition. At the same time, large fixed costs could also induce the monitor to adopt an auditing strategy, not unlike what OIRA does when flagging economically significant rules. How an agency would adapt to these auditing strategies would depend on the auditing criteria as well as the number of monitors it faces. The more monitors and number of criteria, the more difficult it may be for the agency to adopt a consistent response strategy.

In short, the marginal and fixed costs can result in cross-cutting incentives to agencies. Some of these incentives are themselves dependent on the number of monitors agencies face as well as their salience, and on possible auditing strategies that monitors might adopt. It is thus ambiguous as a matter of theory whether a strategic agency will be more likely to bundle or split when facing adverse oversight. The question must be resolved empirically and with attention to the possible heterogeneous effects across types of rules.

${ }^{101}$ See Gersen \& O'Connell, supra note 31, at 1170 (emphasizing relationship between agency behavior and monitoring costs). 


\section{Political and Judicial Review}

At the same time, agencies face slightly different incentives on how to structure their rules whether confronted with review by the President, Congress or the courts. Their ultimate bundling decisions may thus vary depending on which overseer they are likely to face most often. So this section focuses more specifically on various monitors in the administrative state: the incentives they create as well as the ability, if any, to bundle and split agency rules themselves.

\section{a. Office of Information and Regulatory Affairs}

The President's principal regulatory check is exercised through a centralized process coordinated by the Office of Information and Regulatory Affairs (OIRA). ${ }^{102}$ By executive order, a bipartisan series of presidents have required executive agencies to submit proposed and final rules to OIRA for review. ${ }^{103}$ In particular, these agencies must submit "significant" rules, including those deemed "economically significant," that is, expected to cost a $\$ 100$ million or more. ${ }^{104}$ Economically significant rules are more likely to be publicly salient, thus heightening the risk of presidential reversal. ${ }^{105}$ Agencies seeking to avoid that outcome would thus benefit from splitting costly rules into parts - each of which falls beneath the $\$ 100$ million threshold. ${ }^{106}$ So, for example, an economically significant rule with an expected impact of $\$ 150$ million in a given year could be split into two separate rules, each of which is expected to cost $\$ 75$ million in that year. Neither of these rules would now

${ }^{102}$ See Nicholas Bagley \& Richard L. Revesz, Centralized Oversight of the Regulatory State, 106 COLum. L. Rev. 1260, 1261 (2006); Cass R. Sunstein, The Office of Information and Regulatory Affairs: Myths and Realities, 126 HARV. L. REV. 1838, 1839 (2013).

${ }^{103}$ More precisely, any agency that is not a statutorily-defined "independent regulatory agency" must submit regulatory actions to OIRA for review. See Exec. Order No. 12,866 § 3(b), 3 C.F.R. 638, 641 (defining an "agency" as under 44 U.S.C. § 3502(1) and excluding those agencies specified in 44 U.S.C. § 3502(10)).

${ }^{104}$ Exec. Order No. 12,866 § 6(a)(3)(B), 3 C.F.R. 638, 645 (1994). To be significant, a regulatory action must meet at least one of four sets of flexible criteria: it might raise potential inconsistencies with other agencies, "materially alter the budgetary impact of" certain programs, invoke "novel legal or policy issues," or be economically significant.

${ }^{105}$ Public logs also reveal that such rules are more likely to become the subject of meetings between OIRA staff and interested parties, suggesting heightened public scrutiny as well. See Steven Croley, White House Review of Agency Rulemaking: An Empirical Investigation, 70 U. CHI. L. REV. 821, 844, 871-72 (2003).

${ }^{106}$ See Donald R. ARbucKLE, OIRA AND PRESIDENTIAL REgUlatory REVIEW 15 (2008) (observing that agency officials often "divided potential major rules into two or more non-major components, and in other cases they might argue that the estimated costs or benefits were under the $\$ 100$ million threshold"); Declaration of Richard B. Belzer at 9, Tafas v. Dudas, No. 178-2 (E.D. Va. Dec. 27, 2007), available at http://www.rbbelzer.com/uploads/7/1/7/4/7174353/tafas_ex-21-belzerdeclaration.pdf ("During my tenure in OIRA, I often observed agencies attempt to split draft regulations into smaller parts so as to avoid exceeding the $\$ 100$ million threshold for a 'major' or 'economically significant' regulation, presumably in hopes of avoiding the requirements to prepare a Regulatory Impact Analysis."); Note, OIRA Avoidance, supra note 6 at 1002. 
be designated as economically significant, thus effectively lowering the scrutiny of executive oversight.

A strategic agency could also bundle a rule with high benefits and low costs with other rules it wishes to pursue that, standing alone, would not meet a costbenefit criterion. Say, for example, that a regulation restricting air pollution would yield $\$ 100$ million in benefits and $\$ 50$ million in costs. Another regulation dealing with reporting requirements might promise $\$ 1$ million in benefits, but at a cost of $\$ 5$ million - this rule on its own would not be cost-benefit justified. Combining these two rules, however, would result in a regulation with $\$ 101$ million in benefits and $\$ 55$ million in costs, now passing a cost-benefit test. Regulatory impact analysis also reveals the distributional effects of rules. ${ }^{107}$ Thus, agencies facing public criticism from certain groups can split proposed rules before finalizing them in order to favor specific populations. ${ }^{108}$

All of these incentives are intensified by the similar thresholds and criteria set by the Unfunded Mandates Reform Act (UMRA). ${ }^{109}$ UMRA directs agencies to assess regulatory impacts on state, local, and tribal governments as well as the private sector. ${ }^{110}$ In particular, agencies must draft cost-benefit analyses for rules expected to cost $\$ 100$ million or more. ${ }^{111}$ OIRA is charged with compiling those analyses and forwarding them to the Congressional Budget Office. ${ }^{112}$ While monitoring by OIRA and Congress appears to be superficial, agencies seeking to avoid associated litigation risk have an increased incentive to split the rule into parts that fall below the UMRA threshold. ${ }^{113}$

For its part, OIRA has attempted to counter such strategic behavior by rebundling these rules into one rule now categorized as economically significant. In fact, according to a former OIRA branch chief, OIRA once had an informal agreement with the Environmental Protection Agency (EPA) that EPA would submit for review rules that cost over $\$ 25$ million dollars per year. ${ }^{114}$ The idea was to deter EPA from tactical splitting to duck the $\$ 100$ million threshold. More recently, OIRA has issued similarly sensitive guidance under President Trump's aforementioned 2-

${ }^{107}$ Circular A-4 was issued by the Office of Management and Budget in 2001 to provide "guidance to Federal agencies on the development of regulatory analysis." It states that "regulatory analysis should provide a separate description of distributional effects (i.e., how both benefits and costs are distributed among sub-populations of particular concern) so that decision makers can properly consider them along with the effects on economic efficiency." See Office of Mgmt. \& Budget, Exec. Office of the President, Circular A-4, Regulatory Analysis 14 (2003) (hereinafter Circular A-4), available at http://www.whitehouse.gov/omb/circulars_a004_a-4.

${ }^{108}$ Emery interview, supra note 59.

10915 U.S.C. $\S 1532(a)$.

${ }^{110} \mathrm{Id}$.

${ }^{111}$ Id. (in inflation-adjusted annual expenditures).

$112 \mathrm{Id}$.

${ }^{113}$ See Connor Raso, Agency Avoidance of Rulemaking Procedures, 67 ADMIN. L. REV. 65, 105 (2015) (observing that "OIRA lacks the power to block rules where the agency avoided the UMRA" and that "[a]gencies that run afoul of OIRA risk only a negative report to Congress").

${ }^{114}$ See Jennifer Nou, Agency Self-Insulation Under Presidential Review, 126 HARV. L. REV. 1755, 1837 (2013) (citing Email from Arthur Fraas, former chief of the Natural Resources, Energy, and Agriculture Branch, Off. of Info. Reg. Affairs, to atuhor (May 18, 2012, 08:39 EST) (on file with author and cited with permission)). 
for-1 executive order. ${ }^{115}$ In particular, the guidance warns agencies not to "artificially bundl[e] provisions that are not logically connected in a single regulatory action." 116 OIRA acknowledges that agencies may very well have good reasons to package both regulatory and deregulatory provisions into one rulemaking, but warns that OIRA may ask them to split the rules into separate regulatory and deregulatory provisions absent any discernable rationale. ${ }^{117}$

To start to assess whether those agencies subject to OIRA review behave differently from those that are not, Table 3 below considers a more general set of political features and their relationship with bundling in proposed and final rules. For now, consider the first line of the table, which indicates that executive agencies include about 4.8 subjects in final rules, and that independent agencies include about 3.8 subjects - a difference of about one unit, which is significant at any conventional level, as revealed by the small p-value. This suggests that some aspect of the statutory portfolio or oversight environment of executive agencies induces them to bundle more often. This same basic pattern exists for proposed rules, as shown in the bottom panel of the table.

\begin{tabular}{|l|l|c|c|c|}
\hline Table 3: Political Environment and Bundling Behavior \\
\hline \multirow{4}{*}{ Final Rules } & \multicolumn{1}{|c|}{ Political Feature } & No & Yes & Difference \\
\hline & Executive Agency & 3.78 & 4.76 & $0.98^{* *}$ \\
\cline { 2 - 5 } & Election Year & 4.76 & 4.52 & $-0.24^{* *}$ \\
\cline { 2 - 5 } & Presidential Election Year & 4.72 & 4.48 & $-0.24 * *$ \\
\cline { 2 - 5 } & Republican President & 4.77 & 4.59 & $-0.18^{* *}$ \\
\cline { 2 - 5 } & Divided Government & 4.59 & 4.74 & $0.15^{* *}$ \\
\hline \multirow{4}{*}{ Proposed Rules } & Executive Agency & 3.36 & 4.58 & $1.22^{* *}$ \\
\cline { 2 - 5 } & Election Year & 4.55 & 4.25 & $-0.3 * *$ \\
\cline { 2 - 5 } & Presidential Election Year & 4.52 & 4.1 & $-0.42^{* *}$ \\
\cline { 2 - 5 } & Republican President & 4.76 & 4.14 & $-0.62^{* *}$ \\
\cline { 2 - 5 } & Divided Government & 4.3 & 4.54 & $0.24 * *$ \\
\hline
\end{tabular}

\section{b. Congress}

Congress' main opportunity to veto a regulation arises in the form of the Congressional Review Act (CRA). ${ }^{118}$ After a period of relative dormancy, the tool

\footnotetext{
${ }^{115}$ https://www.whitehouse.gov/sites/whitehouse.gov/files/omb/memoranda/2017/M-17-21-OMB.pdf ${ }^{116} \mathrm{Id}$.

${ }^{117} \mathrm{Id}$.

118 Pub. L. No. 104-121, 110 Stat. 871 (1996) (codified at 5 U.S.C. §§ 801-08 (2012)). Congress, of course, has many other tools at its disposal, including appropriations riders and the like. For relevant discussion, see Jack M. Beermann, Congressional Administration, 43 SAN DIEGO L. REV. 61 (2006).
} 
has recently been revived to great effect under the Trump Administration. ${ }^{119}$ The Act requires agencies to submit its final rules to both congressional houses and the Comptroller General. ${ }^{120}$ In turn, both houses of Congress can pass a fast-tracked joint resolution of disapproval which, if signed by the President - or passed by twothirds of both houses over a presidential veto - nullifies the regulation under review. ${ }^{121}$ Importantly, the prescribed text of the joint resolution suggests that Congress can only veto entire rules, not just component parts - a reading supported by the legislative history. ${ }^{122}$ Furthermore, the resolution's up-or-down vote prohibits any amendments, foreclosing the possibility that the rule could be split on the floor. ${ }^{123}$ At the same time, legislators are unable to bundle multiple rules into the same joint resolution of disapproval, requiring promulgated rules to be considered separately. ${ }^{124}$

On the one hand, as discussed above, agencies have an incentive to split rules under the CRA in order to decrease the risk that Congress would nullify provisions packaged together with the offending provision. In other words, Congress may only dislike one provision in a rule, but nevertheless feel compelled to overturn the entire bundled rule given the constraints of the CRA. Agencies could thus seek to save those vulnerable provisions by hiving them off into a separate rulemaking. On the other hand, agencies may also want to bundle a number of provisions together in order to heighten the consequences of the CRA's all-or-nothing quality. By packaging highly favorable provisions into a rule, an agency could make it less likely for Congress to strike the rule down at all - especially since the CRA does not allow agencies to promulgate any "substantially similar" rules once nullified. ${ }^{125}$

To explore the possibility that disagreement between the branches might affect bundling behavior, return again to Table 3 above, which reveals a number of relevant observations. Overall, divided government does not seem to greatly

\footnotetext{
${ }^{119}$ Until recently, the CRA had only been used once to overturn the Occupational Safety and Health Administration's ergonomics standard in March 2001. See MORTON ROSENBERG, CONG. RESEARCH SERV., RL 30116, CONGRESSIONAL REVIEW OF AGENCY RULEMAKING: AN UPDATE AND Assessment of the Congressional Review Act After a DeCAde, Cong. Research SERVICE REPORT FOR CONGRESS 6 (2008); Paul J. Larkin, Jr., Reawakening the Congressional Review Act, 41 HARV. J.L. \& PUB. POL'Y 187, 190 (2018) (noting that CRA has been used to veto fifteen Obama-era regulations).

1205 U.S.C. $§ 802$. More specifically, agencies must submit a report that contains the rule, a concise general statement describing the rule, and its proposed effective date.

${ }^{121} \mathrm{Id}$.

1225 U.S.C. $§ 802$ (a) (Supp. III 1997). “"That Congress disapproves the rule submitted by the relating to ___ and such rule shall have no force or effect.' (The blank spaces are to be appropriately completed)." See Morton Rosenberg, Whatever Happened to Congressional Review of Agency Rulemaking?: A Brief Overview, Assessment, and Proposal for Reform, 51 ADMIN. L. REV. 1051, 1066 (1999) (concluding that "the statutory structure and legislative history of the review provision strongly indicates that Congress intended the process to focus on submitted rules as a whole, and not to allow veto of individual parts").

${ }^{123}$ Id. at 1064-65.

${ }^{124}$ See Larkin, supra note 119, at 251 (noting proposed legislative amendments "allowing Congress to bundle more than one rule into a joint resolution of disapproval rather than consider them one at a time").

1255 U.S.C. $\S 801(\mathrm{~b})(2)$.
} 
influence the extent of bundling. For final rules, the number of subjects is about the same, regardless of divided government, increasing by about 0.15 units during divided government; for notices, the number of subjects is greater during times of divided government, but likewise only modestly so, increasing by about 0.24 units. This pattern suggests that conflict with Congress may modestly increase bundling by agency officials, inspired by the CRA or other congressional tools.

To examine the CRA more closely, consider that the CRA is most effective during transitions to unified government after the White House changes parties. By its own terms, the CRA is limited — the fast-track procedures are available for only 60 days after Congress receives the rule. This means that Congress can reach only into recent regulatory history and is barred from attacking regulations issued even several months earlier. It may only be in this narrow window - when Congress and the president both oppose recently issued regulations - that one is most likely to find effective congressional opposition.

The rules most likely to be subject to these effects, therefore, are those issued in the final months of a presidential administration, particularly the "midnight" period after the presidential election but before the inauguration of the next president. ${ }^{126}$ However, if one examines notices and rules issued in November, December, and January of the second terms of the Clinton, G.W. Bush, and Obama administrations, and compares bundling to the notices and rules issued in those same months of the year prior, one does not in fact see notable changes in bundling behavior. This suggests the modest effects noted above derive from other congressional tools or reflect other dynamics outside of this simple probing exercise. ${ }^{127}$

There is, however, some evidence that political salience matters. The results suggest that elections drive down bundling behavior. This is evident from the "election year" rows, which compare years with a congressional election against odd years. There, we see a modest downtick in bundling behavior, on the order of 0.24 for final rules, or 0.3 for proposed rules. This effect, moreover, appears more pronounced for presidential election years. These effects may reflect a president downgrading regulatory projects in the lead up to the election, ${ }^{128}$ so as to maintain greater message control. Relatedly, they may reflect the increased incentives of Members of Congress to highlight pending regulatory issues they regard as unpopular.

\footnotetext{
${ }^{126}$ See, e.g., Edward H. Stiglitz, Unaccountable Midnight Rules? A Normatively Informative Assessment, 17 NYU J. LEGIS. \& PUB. POL'Y 137 (2014).

${ }^{127}$ E.g., the statutes that occupy agencies' attention may happen to be different during divided government than unified government, and for reasons entirely outside of strategic considerations.

128 This downgrade hypothesis is supported by the fact that it appears that Republican administrations tend to bundle somewhat less often than Democratic administrations. Though this effect is more pronounced for proposed than final rules, it suggests that bundling is contrary to the agendas of regulatory minimalism and deregulation associated with Republican administrations.
} 


\section{c. Courts}

Finally, agency actions are subject to oversight by the courts, which can bundle and split regulations during litigation as well as in the remedial phase. During litigation, aggrieved parties can move to consolidate or coordinate judicial review of separate regulations, or courts can sua sponte issue orders to do so as well. These "batching" decisions are an exercise of courts' powers to manage multiple lawsuits sharing common questions of law or fact. ${ }^{129}$ They amount to the judicial ability to bundle or split rules under the auspices of a single case to review.

Courts can also bundle or split rules at the remedial phase. They can vacate rules as a whole or simply sever individual provisions found to be illegal. To make this decision, courts usually apply a two-part test: First, they will ask whether the agency would have promulgated the rule even without the unlawful provision. ${ }^{130}$ If so, they will then ask whether the remainder of the rule would still be operative. ${ }^{131}$ On remand, the action taken by the agency with respect to that rule will bear the mark of that remedial decision. For instance, if the agency addresses a provision that the court had previously vacated and severed from the remainder of the rule, the provision may stand alone in the renewed effort, effectuating a form of splitting. Alternatively, a reviewing court might determine that the agency has neglected a dimension of the problem. On remand, agencies may decide to address those additional issues in a single rulemaking that might otherwise have been treated separately.

How agencies will behave in anticipation of judicial review is ambiguous as a matter of theory. More judicial scrutiny could lead to more bundling, which may help to obscure agency policy innovations. It may be harder for commenters, litigants, and judges to parse problematic parts of a rule if bundled with many unproblematic parts. Such a dynamic plausibly leads agencies to bundle issues more often when they face an antagonistic court. That said, the relationship between agency bundling and judicial review could also plausibly run the opposite way: agencies may bundle less under more scrutiny. For instance, if courts recognize the act of bundling itself as a potential foul, increasing the odds of a court setting aside a rule on arbitrariness or other grounds, ${ }^{132}$ agencies could heed this danger by decreasing bundling under conditions of judicial scrutiny. Put differently, more

\footnotetext{
${ }^{129}$ Federal Rules of Civil Procedure, Rule 42(a)(1)-(2) (permitting courts to "join for hearing or trial any or all matters at issue in the actions" and "consolidate the actions" if the "actions before the court involve a common question of law or fact[.]" Several circuits, such as the D.C. Circuit and the Ninth Circuit, have designed rules to promote efficiency by "'batching' [] appeals that implicate analogous questions or similar legislation before one argument panel and designating 'lead cases' in which the panel opinion would affect a group of subsequent matters presenting a common issue." See Carl Tobias, Fourth Circuit Publication Practices, 62 WASH. \& LEE L. REV. 1733, 1754 (2005) (citing NinTH CiRCUIT EVAlation COMM. INTERIM REPORT 8-16 (March 2000) at 7 ("describing the Ninth Circuit's use of lead cases and batching")).

${ }^{130}$ See Charles W. Tyler \& E. Donald Elliott, Administrative Severability Clauses, 124 YALE L.J. 2286, 2296 (2015).

${ }^{131} I d$. Sometimes, agencies themselves include severability clauses to help inform the court's analysis, but the practice is uncommon. $I d$.

${ }^{132}$ See infra Part III.C.
} 
forceful judicial policing could lead to more rule-splitting by litigation-adverse agencies.

By way of preliminary examination, consider the following measure of judicial scrutiny: the extent to which there is preference divergence based on the partisan identity of the judge's nominating party. ${ }^{133}$ The composition of the D.C. Circuit is most relevant, as that circuit has the greatest focus on administrative law matters. ${ }^{134}$ Moreover, because challenges to agencies rules almost never reach the Supreme Court, the D.C. Circuit is in all likelihood the final resting place for administrative controversies. ${ }^{135}$ To produce the measure of preference divergence, we first determine the proportion of active judges in a given year on the DC Circuit who were appointed by a Republican president. ${ }^{136}$ During Democratic regimes, we use this quantity as a metric of judicial preference divergence; during Republican regimes, we use one minus this quantity as the relevant metric. Thus, larger figures reflect a larger number of D.C. Circuit judges appointed by a president of the opposite party as the sitting president.

According to this measure, judicial scrutiny tends to be relatively high during the first term of an administration, before the sitting president has had an opportunity to appoint sympathetic judges to the Circuit. During the first administrations of Presidents G.W. Bush, Obama, and Trump, for example, the average judicial scrutiny score is 0.62 - indicating that almost two-thirds of the active judges on the circuit were appointed by a president of the opposing political party. By comparison, the average score during the second administrations is 0.37 , indicating, that is, that in their second terms presidents face judges appointed by the opposing president closer to one-third of the time.

The question of interest is whether agency bundling increases, decreases, or seems unaffected by changes in judicial scrutiny. Perhaps surprisingly, our initial results suggest that judicial preference divergence is unrelated to bundling behavior, indicating that other regulatory actors may be more significant. The correlation between judicial scrutiny and bundling is virtually zero. ${ }^{137}$ Moreover, decomposing

\footnotetext{
${ }^{133}$ There is a robust debate on the appropriate method for measuring judicial preferences. Compare, e.g., LeE EPstein. William M. LANDES \& Richard A. Posner, The BehaVior of Federal Judges (2013) with Adam Bonica \& Maya Sen, A Common-space Scaling of the American Judiciary and Legal Profession, Political ANALYsis 114 (2017). See Joshua B. Fischman \& David S. Law, What Is Judicial Ideology, and How Should We Measure It?, 29 WASH. U. J.L. \& POL'Y 133 (2009). Future empirical work should extend the work here using alternate measures of judicial ideology.

${ }^{134}$ See John G. Roberts, Jr., What Makes the D.C. Circuit Different? A Historical View, 92 VA. L. REV. 375, 376-77 (2006).

${ }^{135} \mathrm{Id}$.

${ }^{136}$ We calculate this quantity based on biographical data from the Federal Judicial Center. See Federal Judicial Center, https://www.fjc.gov/

${ }^{137}$ Specifically, the correlation between the two measures is 0.007 , and it is not significant at the conventional level even with over 50,000 observations. More sophisticated examinations, available on request, that for example look within presidential administrations, or within agencies, show the same pattern: judicial scrutiny bears almost no relationship to bundling behavior, on average. Of course, that null results may reflect heterogeneous effects: scrutiny may increase bundling for some types of rules and decrease it for other types of rules, producing, on average, an effect that approaches zero. Such explanations call for further attention and investigation. But to a first approximation, there does
} 
the regulatory actions along various dimensions results in the same basic finding that no influence persists. There seems to be no relationship, that is, between judicial scrutiny and bundling for proposed and final rules, nor executive agencies and independent agencies. While other measures of judicial scrutiny should be considered, these initial results may suggest that other institutional monitors like the President and Congress are stronger motivators of bundling behavior than the courts.

There are many potential explanations for this possibility. First, the splitting incentives described above may operate on some rules, and the bundling incentives described above operate on other rules, combining to an essentially null effect on average. Second, it is also possible that courts do not police this question of bundling as assiduously as they might. ${ }^{138}$ Finally, it may also be that agencies do not much heed court composition for a variety of reasons. For instance, agencies are unlikely to be able to predict the partisan composition of their particular judicial panels. Many panel assignments are random or otherwise influenced by factors outside the litigants' control. ${ }^{139}$ It is therefore difficult for agencies to structure their rulemaking behavior in anticipation of a particular set of judges. Moreover, only a highly limited proportion of agency rules are subject to litigation, and even then, the risks of such litigation are not always predictable ex ante. ${ }^{140}$ The remedies may also not be clear in advance — courts often exercise their equitable discretion in deciding whether to use vacatur as a judicial remedy. ${ }^{141}$

Similarly, the standards that courts use to bundle and split rules during litigation are also murky. The D.C. Circuit, for example, distinguishes between consolidated and coordinated cases which result in either a single or multiple judicial opinions. ${ }^{142}$

not appear to be any relationship between this measure of judicial scrutiny and our maintained measure of agency bundling.

138 See infra Part III.

139 See Michael Abramowicz \& Maxwell Stearns, Defining Dicta, 57 STAN. L. REV. 953, 1009 (2005)

("In the Courts of Appeals, panels are the product of random draws of three among a larger set of members of the court."). But see Adam S. Chilton \& Marin K. Levy, Challenging the Randomness of Panel Assignment in the Federal Courts of Appeals, 101 CORNELL L. REV. 1, 55 (2015); Marin K. Levy, Panel Assignment in the Federal Courts of Appeals, 103 CORNELL L. REV. 65 (2017).

${ }^{140}$ See Raso, supra note 113.

${ }^{141}$ See Ronald M. Levin, "Vacation" at Sea: Judicial Remedies and Equitable Discretion in Administrative Law, 53 DUKE L.J. 291, 323 (2003) (describing a "a variety of situations in which courts have continued to adhere to the kind of flexibility that is characteristic of traditional equitable discretion" when deciding whether or not to vacate a rule after remand).

${ }^{142}$ Consolidated cases there are "treated as one appeal for most purposes" in that they "follow a single briefing schedule, they are assigned for hearing on the same day before the same panel, argument time is allotted to the cases as a group, and they are decided at the same time." D.C. Circuit Handbook of Practice and Internal Procedures (as amended March 2018) at 24, available at https://www.cadc.uscourts.gov/internet/home.nsf/Content/VL\%20-\%20RPP\%20$\% 20$ Handbook\%202006\%20Rev\%202007/\$FILE/HandbookMarch2018WithTOCLinks.pdf. DC Circuit internal procedural rules also provide, however, that even after a case is consolidated individual litigants still maintain the ability to file separate motions. Id. Consolidation, in other words, yields a single judicial opinion informed by a single set of briefs and oral arguments.

Coordinated cases, by contrast, results in separate judicial opinions informed by separate briefs; they are still heard, however, before the same judicial panel. See Gregory E. Wannier, How Many Suits Is Too Many? Consolidation and Coordination Possibilities in EPA Climate Litigation (Oct. 22, 2010) ("Case coordination involves hearing multiple cases before the same panel, with a 
It does not, however, provide clear guidance on how judges should choose one approach over the other, leaving it instead to their managerial discretion. To illustrate what can be at stake, return again to EPA's Obama-era greenhouse gas regulations. Recall that EPA had initially opened a single rulemaking docket, but then issued four separate rules dealing with carbon dioxide: The Endangerment Finding determined that carbon dioxide endangered "public health or welfare." 143 The next Tailpipe Rule set emission standards for cars and light trucks. ${ }^{144}$ The following Triggering Rule determined the Clean Air Act required major stationary sources to obtain construction and operating permits. ${ }^{145}$ The Tailoring Rule then limited the requirement only to the largest stationary sources. ${ }^{146}$

A coalition of businesses, interest groups, and U.S. Representatives filed a motion to coordinate review of all four rules together before the same judicial panel. In their view, the cases were substantively interrelated so as to "amount[] to a single policy approach" - evidenced by EPA's own concession that the rules are "related."147 These industry groups also characterized EPA's opposition as an attempt to dismiss their challenges based on standing principles, particularly dealing with injury-in-fact and causation. Separate judicial review, they argued, could result in an attempt to call for "a more appropriate forum" in every case, and thereby denying them all forums for review. ${ }^{148}$ One potential motivation for their motion was the hope that the more legally tenuous and politically controversial aspects of the Triggering and Tailoring Rules would bring down the Endangerment Finding with it.

Perhaps unsurprisingly, EPA as well as a coalition of 19 states and the City of New York filed a motion in opposition to coordination. While conceding that the Timing and Tailoring Rules were interrelated enough to warrant consolidation (not mere coordination), it argued that combining review of the Endangerment Finding and Tailpipe Rule would confuse courts with different administrative records and "entirely separate" legal questions. ${ }^{149}$ EPA also pointed out that D.C. Circuit rules allowed petitioners to use evidence outside the administrative record to establish standing, thus mitigating any justiciability concerns. By opposing coordination, EPA

goal of yielding complementary decisions in cases where challenges cover related activities."), http://blogs.law.columbia.edu/climatechange/2010/10/22/how-many-suits-is-too-many-consolidationand-coordination-possibilities-in-epa-climate-litigation/\#_ftn2.

${ }^{143}$ See 42 U.S.C. § 7521(a)(1); Endangerment and Cause or Contribute Findings for Greenhouse Gases Under Section 202(a) of the Clean Air Act, 74 Fed. Reg. 66,496 (Dec. 15, 2009).

${ }^{144}$ Light-Duty Vehicle Greenhouse Gas Emission Standards and Corporate Average Fuel Economy Standards; Final Rule, 75 Fed. Reg. 25,324 (May 7, 2010).

${ }^{145}$ Reconsideration of Interpretation of Regulations that Determine Pollutants Covered by Clean Air Act Permitting Programs, 75 Fed. Reg. 17,004 (Apr. 2, 2010).

${ }^{146}$ Prevention of Significant Deterioration and Title V Greenhouse Gas Tailoring Rule, 75 Fed. Reg. 31,514 (June 3, 2010).

${ }^{147}$ More specifically, their argument was that they "taken together...[these rules] will subject [greenhouse gases] emitted from stationary sources to [Prevention of Significant Deterioration, PSD] requirements, and limit[] the applicability of PSD requirements to GHG sources on a phased-in basis." See Wanier, supra note 149.

${ }^{148}$ Id.

${ }^{149} \mathrm{Id}$. 
was likely hedging its bets. Even if it met one judicial panel hostile to its efforts to address climate change, the agency might still be able to salvage parts of its program before another more-friendly panel. ${ }^{150}$

\section{Implications}

This Part now takes a step back to consider the phenomenon of regulatory bundling in terms of the rulemaking process. After reflecting upon the role of bundling in the notice-and-comment process, the next section then considers the broader implications of regulatory bundling for political monitors and the courts. If the phenomenon derives from the influence of narrow special interests, then tools like the single-subject rule or a line-item veto may be appropriate. Even if it does not, revised doctrines of judicial review may nonetheless be wise to preserve the value of public participation. At the same time, regulatory bundling can yield benefits as well. So the normative desirability of these general reforms requires further empirical analysis or a case-by-case approach attuned to the specific merits of a particular bundling decision.

\section{A. Regulatory Process}

Notice-and-comment rulemaking, as its name suggests, requires agencies to give notice of a proposed rule in the Federal Register and then provide parties with an opportunity to submit comments. ${ }^{151}$ The agency must base the rulemaking upon consideration of those comments and include a statement of basis and purpose in the final rule adopted. Final rules adopted according to this procedure operate with the force of law. ${ }^{152}$ On the one hand, public comments can improve regulations by allowing information-gathering, spurring political monitoring, and fostering public deliberation. ${ }^{153}$ On the other hand, the process can also facilitate capture by special interest groups or poorly informed individuals, as well as politicize an otherwise evidence-based issue. $^{154}$

${ }^{150} \mathrm{Id}$.

1515 U.S.C. $\$ 553(2000)$.

1525 U.S.C. $\S \S 553(\mathrm{~b})(\mathrm{c})(2000)$.

153 See Mark Fenster, The Opacity of Transparency, 91 IowA L. REV. 885, 896-99 (2006) 154. See id. at 918-19. 
Figure 5: Histograms of Bundling Subjects
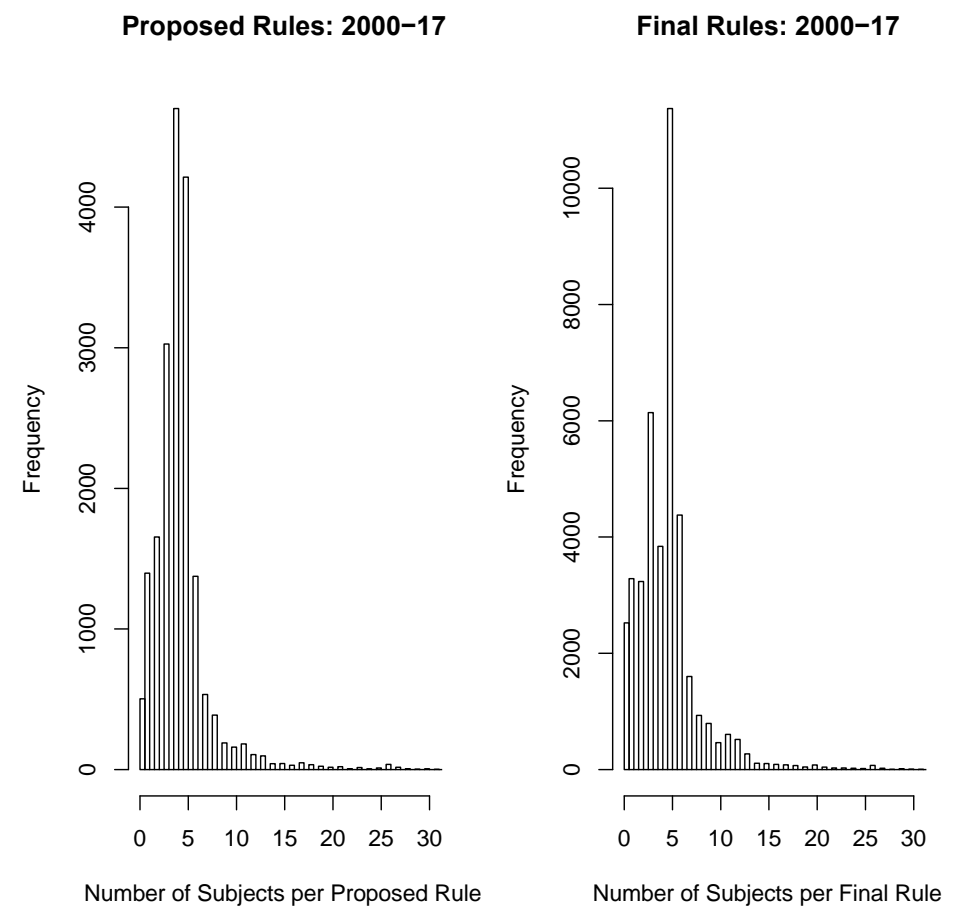

To better understand how the procedure may influence bundling, Figure 5 above displays a histogram of the number of subjects in proposed (left panel) and final rules (right panel). As is evident in the figure, the number of subjects is right skewed, with many rules listing very few subjects, and a distinct minority of rules listing a large number of subjects. Interestingly, final rules contain more subjects than proposed rules: the average number of subjects in a proposed rule is 4.4 subjects, and the corresponding average for final rules is 4.7 subjects. This observation may suggest that agencies may be increasing bundling through the notice and comment process - perhaps a kind of "bundling creep" whereby agencies include additional issues in a final rule.

To examine this possibility of creep, consider the evolution of bundling within rulemaking efforts. ${ }^{155}$ To do so, we built a software program to match proposed with final rules, thereby allowing us to examine how bundling changes across a rule's life cycle. Over the series, we identify almost 14,500 matches between proposed and final rules, thus accounting for over three-quarters of all proposed rules. $^{156}$

\footnotetext{
${ }^{155}$ Note that earlier we examined the average number of subjects in proposed and final rules within agencies, and found those correlations to be strong - agencies that list many subjects in their proposed rules also do so in final rules. Here, we look within rulemaking efforts.

${ }^{156}$ The remaining one-quarter of "orphan" proposed rules fall into a variety of categories. For instance, agencies not infrequently withdraw proposed rules, and later re-issue revised versions of the same. For the later parts of the series, many proposed rules will not have completed the rulemaking
} 


\section{Figure 6: Bundling in Proposed and Final Rules}

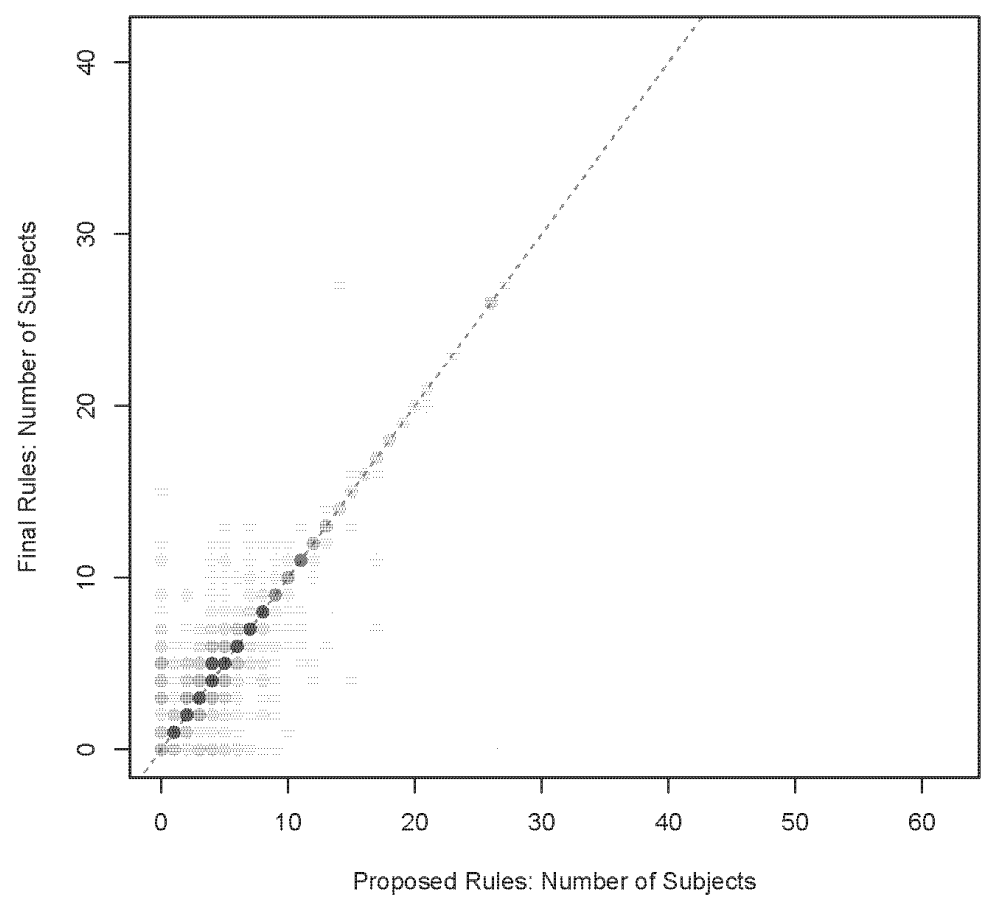

Examining the evolution of bundling within a rulemaking effort reveals several features. First, most rules that start out with extensive bundling finish with extensive bundling. The correlation between the number of subjects in proposed and final rules is strongly positive at 0.80 . Figure 6 above plots the number of subjects in the final rule against the number of subjects in the matched proposed rule. As is evident by the darker shading, indicating a density of rules, most rules fall along the line of perfect correspondence. Second, consistent with the findings above, when rules change the number of subjects in a rulemaking effort, they tend to increase them. This is also evident from Figure 6, which shows a greater density of rules above the line of correspondence than below it.

Quantitatively, fully one-quarter of rules increase the number of subjects listed through the rulemaking process (25 percent); almost seven-in-ten rules

process - a rule proposed in 2017, for example, is quite likely not to have been finalized in our dataset; the orphan rate in 2017 is over double the rate at the start of the series. In other cases, our algorithm may miss references to proposed rules in the final rules, for instance because the agency used non-standard citation or recorded the citation to the proposed rule incorrectly. However, we suspect such instances are rare and, of more importance, essentially random. The algorithm works by searching final rules for references to proposed rules, and this may also lead to "false" matches, if for example a final rule cites distinct but perhaps related regulatory efforts. Based on an inspection of a random subset of matches, however, we believe the number of false matches to be relatively small and, as above, to operate mainly to introduce an element of noise but not bias. 
maintain the exact number of subjects throughout the process (69 percent); and fewer than one-in-ten decreases the number of subjects from proposed to final rule (6 percent). ${ }^{157}$ As an initial matter, it is possible these findings reflect agency coding practices rather than substantive changes in the regulatory language - a kind of measurement error. Because proposed rules are lower stakes than final rules, rulewriters may not pay much attention to ensuring coding accuracy at the proposal stage. ${ }^{158}$ Before finalizing, however, they may invest more time and effort in ensuring that the list of subjects is complete, as would the Office of Federal Register during review. ${ }^{159}$ Therefore, the increase in subjects at the final rule stage may simply reflect more careful coding efforts. Mitigating this possibility, however, is the fact that public commenters can criticize agencies for incomplete lists of subjects. ${ }^{160}$ Such public scrutiny may help encourage agencies to publish complete subject lists at the proposal stage too.

If so, the results above then likely reflect the incentives generated by the notice-and-comment process in favor of more bundling at the final rule stage. Commenters might raise issues not initially contemplated by the agency, compelling agency officials to address them more specifically in the final rule. While agencies are constrained by the judicial requirement to ensure final rules are a "logical outgrowth" of proposed rules, the requirement has limited bite in practice. ${ }^{161}$ As a result, agencies may address more issues in the final rule to appease stakeholders who possess credible means of delaying or killing the regulatory effort.

Indeed, regulated entities could seek bundling for many reasons. Bundled rules facilitate predictability and planning by simultaneously imposing regulatory obligations. Businesses could thus invest in any necessary compliance technology all at once, instead of on an inefficient, piecemeal basis. Bundled rules could also be attractive to interest groups with wide-ranging agendas, but narrow windows of opportunity to capture a regulatory drafter. Successful lobbyists could extract packages of perks and rewards as the opportunity arises. Relatedly, the revolving door may also facilitate mutually beneficial relationships between agency insiders and industry members. These relationships may result in logrolling between repeat players. Agency staffers, that is, could trade off regulatory favors between regulations at different points in time, thus resulting in rules with more provisions.

\footnotetext{
${ }^{157}$ Also recall that, on average, agencies increase the number of subjects from proposed to final rule by almost one unit (0.9).

${ }^{158}$ See Emery interview, supra note 59. Final rules, unlike proposed rules, are legally binding and subject to litigation as final agency action. 5 U.S.C. $\$ 704$.

159 See Swidal interview supra note 38.

${ }^{160}$ See, e.g., National Council of Teachers of English (Nov. 17, 2017) (suggesting that Department of Education "add 'literacy' to the list of subjects"), https://www.regulations.gov/document?D=ED2017-OS-0078-1354.

${ }^{161}$ Discussion regarding various circuit practices focusing on logical outgrowth of the text v. preamble v. comments. General circuit disparities and unpredictability of application.
} 


\section{B. Innovative Controls}

Regulatory bundling as a concept and phenomenon offers new perspectives on the kinds of controls available to agency monitors. The standard account usually contemplates the President, Congress, and the court striking down entire regulations. Disaggregating rules, however, opens up new possibilities for the kinds of tools overseers can use to exercise oversight. As discussed further below, the normative desirability of bundling and splitting remains contested and uncertain. The net effects require further empirical examination, the conclusions of which will help to inform whether and the extent to which these reforms should be adopted.

\section{Line-Item Vetoes}

The line-item veto has traditionally been understood as the ability of executive officials to cancel or nullify specific provisions of bills before signing them. ${ }^{162}$ While the mechanism has been well-studied in the statutory context, ${ }^{163}$ its implications for the regulatory state have gone largely unexplored. One explanation may be the relatively mysterious nature of the OIRA review process: few recognize, for example, that OIRA exercises a form of the line-item veto for regulations. ${ }^{164}$ After agencies submit their proposed and final rules for review, OIRA has the ability to cross out specific provisions as well as broader language unrelated to specific regulatory costs. ${ }^{165}$ Many have criticized this practice as legally illegitimate or unwise intermeddling in agency expertise. ${ }^{166}$

\footnotetext{
${ }^{162}$ See Indridi H Indridason, Executive Veto Power and Credit Claiming: Comparing the Effects of the Line-Item Veto and the Package Veto, 146 PUBLIC CHOICE (2011).

${ }^{163}$ See, e.g., Glenn Abney \& Thomas P. Lauth, The Line-Item Veto in the States: An Instrument for Fiscal Restraint or an Instrument for Partisanship?, 45 PUB. ADMIN. REV. (1985); John R. Carter \& David Schap, Line-Item Veto: Where is Thy Sting?, 4 J. ECON. PERSPECTIVES (1990); James A. Dearden \& Thomas A. Husted, Do Governors Get What They Want?: An Alternative Examination of the Line-Item Veto, 77 PUBLIC ChOICE (1993); James J. Gosling, Wisconsin Item-Veto Lessons, 46 PuB. Admin. Rev. (1986); Pat Thompson \& Steven R. Boyd, Use of the Item Veto in Texas, 19401990, 26 STATE \& LOCAL GOV. REV. (1994).

${ }^{164}$ Sunstein, supra note 102, at 1839 (2013) (observing that "the role of OIRA and the nature of the OIRA process remain poorly understood"). One exception is Steven Croley who has observed that "whereas the president lacks the ability to veto selective pieces of legislation, he enjoys a "line-item veto,' so to speak, of agencies' regulatory initiatives." See STEVEN P. CROLEY, REGULATION AND PUBLIC INTERESTS 97 (2008).

${ }^{165}$ See Lisa Heinzerling, Inside EPA: A Former Insider's Reflections on the Relationship Between the Obama EPA and the Obama White House, 31 PACE ENVTL. L. REV. 325, 344 (2014) (describing how OIRA "offered line-by-line edits of regulatory proposals"). The latter ability is often referred to as the "narrative veto" in the statutory context. See Abney Glenn \& Thomas P. Lauth, Gubernatorial Use of the Item Veto for Narrative Deletion, 62 PUB. ADMIN. REV. (2002).

${ }^{166}$ See, e.g., Heinzerling, supra note 165; Wendy E. Wagner, A Place for Agency Expertise:

Reconciling Agency Expertise with Presidential Power, 115 CoLuM. L. REV. 2019, 2045 (2015).
} 
Appreciating regulatory bundling, however, allows for a more nuanced assessment of the OIRA process. One hypothesis in the statutory context is that the line-item veto is a salutary means for the executive to cut back on logrolling and pork barrel politics. ${ }^{167}$ Indeed, this is often the rationale for OIRA review itself: as a means for a nationally-conscious executive to check mission-oriented agencies who impose narrow regulatory costs. ${ }^{168}$ A competing hypothesis, however, is that the line-item veto results in an increase in special-interest bills. ${ }^{169}$ The possibility of a veto itself, in other words, can induce the proposer to include more pork-barrel provisions in the hopes that some survive the veto threat. In fact, some have observed this practice in the regulatory context: Agencies will often add provisions to draft rules as bargaining chips that "would be available" for agencies "to give away" or negotiate during OIRA review in order to protect what they perceive as the most important provisions of a rule. ${ }^{170}$

While most empirical work in the legislative context suggests that the item veto produces either no discernible effect ${ }^{171}$ or only under certain conditions such as divided government, ${ }^{172}$ a natural question, then, is whether these findings extend to the administrative state and how legislative, presidential, and agency preferences interact in the shadow of OIRA's line-item veto. Such evaluations could help inform a more meaningful debate about potential reforms to the OIRA process. These debates, for example, might raise inquiries analogous to those asked in the legislative arena. Instead of a line-item veto, for example, perhaps OIRA should only be granted a "package veto" over the entire regulation, rather than its parts. ${ }^{173}$ Would doing so result in a more productive set of agency-White House dynamics or only more delay and ossification? These perspectives also open up other institutional possibilities such as a line-item congressional veto, which would likely require an amendment to the Congressional Review Act.

\footnotetext{
${ }^{167}$ Id.

${ }^{168}$ See, e.g., Steven Croley, White House Review of Agency Rulemaking: An Empirical Investigation, 70 U. CHI. L. REV. 821, 873-76 (2003); Elena Kagan, Presidential Administration, 114 HARV. L. REV. 2245, 2284-90 (2001).

${ }^{169}$ See David C. Nice, The Item Veto and Expenditure Restraint, 50 J. PoL. (1988); Catherine C. Reese, The Line-Item Veto in Practice in Ten Southern States, 57 PUB. ADMIN. REV. (1997);

${ }^{170}$ See Stuart Shapiro, The Role of Procedural Controls in OSHA's Ergonomics Rulemaking, 67 PUB. ADMIN. REV. 688, 693 (2007).

${ }^{171}$ See Indridadson, supra note 162; John R. Carter \& David Schap, Line-Item Veto: Where is Thy Sting?, 4 J. ECON. PERSPECTIVES (1990); Catherine C. Reese, The Line-Item Veto in Practice in Ten Southern States, 57 PUB. AdMIN. REV. (1997); James J. Gosling, Wisconsin Item-Veto Lessons, 46 Pub. Admin. REV. (1986); Pat Thompson \& Steven R. Boyd, Use of the Item Veto in Texas, 1940 1990, 26 STATE \& LOCAL GOV. REV. (1994).

${ }^{172}$ See Glenn Abney \& Thomas P. Lauth, The Line-Item Veto in the States: An Instrument for Fiscal Restraint or an Instrument for Partisanship?, 45 PUB. ADMIN. REV. (1985); James A. Dearden \& Thomas A. Husted, Do Governors Get What They Want?: An Alternative Examination of the LineItem Veto, 77 Pub. Choice (1993); Adam R. Brown, The Item Veto's Sting, 12 STATE Politics \& POLICY QUARTERLY (2012).

${ }^{173}$ See Indridason, supra note 162.
} 


\section{Single-Subject Rules}

Another potential innovation that bears plain relevance to regulatory bundling is a single subject rule for the administrative state. Single subject rules require a lawmaking body to address only a single "subject." 174 Many state constitutions, for instance, impose such a rule on state legislatures. ${ }^{175}$ The rationale varies from location to location, but tends to be rooted in one or more of the following concerns. ${ }^{176}$ The dominant one is that a piece of legislation with multiple subjects might represent logrolling in which no individual provision enjoys majority support. ${ }^{177}$ Say a piece of legislation that contains issue A does not have majority support, so the drafters join issue B to the bill. If a sufficient number of legislators favor issue B without strongly disfavoring issue A, the bill with both A and B will receive majority support. It might be, however, that neither issue A nor issue $\mathrm{B}$ enjoys majority support on its own, but that both issues become law by virtue of bundling. In this sense, a persistent fear is that logrolling works for the benefit of special interest groups at the expense of the general public.

Another fear is that allowing a piece of legislation to address multiple subjects may increase the size of government beyond the optimal. Bundling allows measures to enter law that, standing alone, would not become law, arguably leading to excessive legislation. Those opposed to the growth of government may thus seek a single subject rule. This position, of course, relies on some notion of the "optimal" size of government, a question about which there is no clear consensus. ${ }^{178}$ Finally, another related concern is that bundling diminishes political accountability. Returning to our example with issues A and B, it is challenging for observers - i.e., voters - to know whether their representatives supported issue A or B. If issue B, say, turns out to harm voters interests, the representative might plausibly defend himself by saying that he, too, opposes issue B, but ultimately voted for the bill to win passage for issue A. That statement may or may not be true and is difficult for the voter to evaluate, thus diminishing accountability.

${ }^{174}$ See Michael D. Gilbert, Single Subject Rules and the Legislative Process, 67 U. PITT. L. REV. 803 (2005).

${ }^{175}$ Id. See also John G. Matsusaka and Richard L. Hasen, Aggressive Enforcement of the Single Subject Rule, 9 ELECTION L. J 399 (2010); Martha J. Dragich, State Constitutional Restrictions on Legislative Procedure: Rethinking the Analysis of Original Purpose, Single Subject, and Clear Title Challenges, 38 HARV. J. ON LEGIS. 103 (2001); Robert F. Williams, State Constitutional Limits on Legislative Procedure: Legislative Compliance and Judicial Enforcement, 17 PUBLIUS: THE JOURNAL OF FEDERALISM 91 (1987); Jeffrey Gray Knowles, Enforcing the One-Subject Rule: The Case for a Subject Veto, 38 HASTINGS L.J. 563 (1986); Rachael Downey et al., A Survey of the Single Subject Rule as Applied to Statewide Initiatives, 13 J. CONTEMP. LEGAL ISSUES 579 (2003); Odishaw, Courtney Paige. Curbing Legislative Chaos: Executive Choice or Congressional Responsibility. 75 Iowa L. Rev. 227 (1988).

${ }^{176}$ See sources cited supra note 175.

${ }^{177}$ See Gilbert, supra note 175.

${ }^{178}$ For an early entry on this question, see Allan H. Meltzer \& Scott F. Richard, A Rational Theory of the Size of Government, 85 J. POL. ECON. 914 (1981). 
Similar normative concerns could also motivate a single-subject rule for the administrative state. Logrolling within an agency or across agencies could produce momentum for a regulatory effort that otherwise would stall. Similarly, agency staff can attach provisions to rules that have been expedited by a political appointee to meet a statutory deadline. ${ }^{179}$ These regulatory riders may escape internal scrutiny due to the speed of the rulemaking and receive only cursory review by an agency head distracted by higher-priority components. Concerns about the size of government also resonate in the regulatory context, as do threats to accountability posed by unelected bureaucrats. ${ }^{180}$ Many of the concerns that animate the single-subject rule are alive and well in the administrative setting.

A rule requiring regulations to deal with one subject at a time could be imposed by statute, executive order or through judicial case law. How to define a "subject" is notoriously difficult as a linguistic and conceptual matter and different institutional actors will likely be informed by different motivating concerns. ${ }^{181}$ Congress, for example, may want to define a "subject" by reference to its own legislative bundles. This approach may require agencies to issue regulations under one statutory grant at a time, rather than pursuant to multiple authorities that upset the preferences of a specific enacting Congress. By contrast, the President may see it as part of his constitutional duty to regulate coherently across all of his delegated authority. So he may want to limit how regulations are bundled in some way to advance his particular priorities or otherwise allow him to claim public credit effectively. ${ }^{182}$

Alternatively, instead of specifying what a "subject" entails in advance, any of these actors, including the courts, could simply impose a duty to explain why a rule is bundled in a particular way. This approach would help mitigate the definitional problem, requiring agencies instead to provide a rationale at whatever level of generality it deemed appropriate. For example, as mentioned, OIRA's guidance under Trump's 2-for-1 executive order requires agencies to explain how regulatory provisions are "logically connected." 183 OIRA then retains the authority to split the regulations as necessary to ensure compliance with its executive order. Courts could similarly require regulatory provisions to be sufficiently related and then grant varying levels of deference to an agency's bundling explanation, as further discussed below. Because regulatory bundling often requires specialized knowledge

\footnotetext{
${ }^{179}$ Emery interview, supra note 59.

${ }^{180}$ See, e.g., RichARD A. EPSTEIN, DESIGN FOR LIBERTY: PRIVATE PROPERTY, PUBLIC ADMINISTRATION, AND THE RULE OF LAW (2011).

${ }^{181}$ See, e.g., Robert D. Cooter \& Michael D. Gilbert, A Theory of Direct Democracy and the Single Subject Rule, 110 Colum. L. REV. 687 (2010) ("Logic and language cannot yield a precise definition of 'subject."'); Daniel H. Lowenstein, Initiatives and the New Single Subject Rule, 1 ELEC. L. J. 35, 47 (2002) ("The difficulty of applying the term 'subject' in a single subject rule . . is that by its very nature, the permissible content of a 'subject' is infinitely and essentially malleable.").

${ }^{182}$ At the state level, there is also the interesting dynamic of the plural or "unbundled" executive, which may result in greater state agency splitting to align with the interests of separate executives. See Christopher R. Berry \& Jacob E. Gersen, The Unbundled Executive, 75 U. CHI. L. REv. 1385, 1404 (2008).

${ }^{183} \mathrm{https} / / /$ www.whitehouse.gov/sites/whitehouse.gov/files/omb/memoranda/2017/M-17-21-OMB.pdf
} 
— for instance, how a program in area $\mathrm{A}$ is likely to affect a program in area $\mathrm{B}$ courts may not feel institutionally competent to assess the decision de novo.

\section{Judicial Review}

\section{a. Soft Looks}

Courts can and do police bundling decisions under arbitrariness review. ${ }^{184}$ This standard - whether or not an agency action is "arbitrary or capricious" — is generally understood as demanding evidence-based explanation. ${ }^{185}$ While courts have sometimes described this review as a "hard look," they are also quick to emphasize that judicial review should be "narrow" and not displace the agency's well-considered judgment. ${ }^{186}$ In practice, judges appear to be fairly deferential to agencies under the test, especially at the Supreme Court ${ }^{187}$ — perhaps invoking it only intermittently to ensure that it remains a credible threat.

This general orientation - a "soft" rather than "hard" look if you will — seems appropriate when it comes to the review of regulatory bundling. One reason is that bundling can be understood in some sense as an agency choice about policymaking form, a choice about which courts are generally deferential if the underlying statute is otherwise silent. ${ }^{188}$ Agencies also possess the comparative expertise necessary to assess the potential benefits and harms of bundling. The practice may, for example, lower compliance costs for regulated industries by imposing one-time investments in technology. Indeed, this was the sensible rationale provided by a Department of Health and Human Services (HHS) final regulation consolidating into one rule what had previously been four proposed and interim final rules. ${ }^{189}$ Bundling could also reflect productive and necessary bargaining between agency actors and political monitors.

1845 U.S.C. $\$ 706(2)(A)$.

185 See Kathryn A. Watts, Proposing A Place for Politics in Arbitrary and Capricious Review, 119 YALE L.J. 2 (2009) (“Current conceptions of 'arbitrary and capricious' review focus on whether agencies have adequately explained their decisions in statutory, factual, scientific, or otherwise technocratic terms.").

${ }^{186}$ See Motor Vehicle Mfrs. Ass'n of U.S., Inc. v. State Farm Mut. Auto. Ins. Co., 463 U.S. 29, 43, 103 S. Ct. 2856, 2866, 77 L. Ed. 2d 443 (1983) ("The scope of review under the "arbitrary and capricious' standard is narrow and a court is not to substitute its judgment for that of the agency."). ${ }^{187}$ See Jacob Gersen \& Adrian Vermeule, Thin Rationality Review, 114 MiCH. L. REV. 1355, 1367 (2016) (observing that agencies win 95 percent of arbitrariness challenges at the Supreme Court and that "the days of systematically aggressive hard look review, as in the D.C. Circuit's decisions from the 1970 s and early 1980 s, are mostly behind us").

188 See SEC v. Chenery Corp., 318 U.S. 80, 85 (1943); N.L.R.B. v. Bell Aerospace Co. Div. of Textron, 416 U.S. 267, 289-90 (1974); Magill, supra note 1).

${ }^{189}$ Modifications to the HIPAA Privacy, Security, Enforcement, and Breach Notification Rules Under the Health Information Technology for Economic and Clinical Health Act and the Genetic Information Nondiscrimination Act; Other Modifications to the HIPAA Rules, 78 Fed. Reg. 5566, 5566 (Jan. 25, 2013) (to be codified 45 C.F.R. pts. 160 and 164) ("This final rule is comprised of four 
At the same time, it is important for courts to continue to use arbitrariness review to invalidate particularly troubling instances of bundling that lack sufficient justification. Consider, for example, the Eleventh Circuit's decision in AFL-CIO v. $O S H A^{190}$ to strike down OSHA's Air Contaminants Standard rule. The case applied a standard more stringent than arbitrary-or-capriciousness due to the underlying statute, but it nevertheless illustrates an approach we view favorably. ${ }^{191}$ After the initial promulgation of "start-up" standards based on already existing federal requirements, ${ }^{192}$ OSHA had managed to issue regulations dealing with only 24 toxic substances. Historically, OSHA had addressed these substances only one a time.

In this bundled rulemaking, however, the agency decided to attempt to deal with 428 substances all at once. In OSHA's view, "it would take decades to review currently used chemicals and OSHA would never be able to keep up with the many chemicals which will be newly introduced in the future." 193 Further, the OSHA chief stated that by treating over four-hundred substances in one regulation, the agency could "make a 20-year leap forward in the level of worker protection in a relatively short time." "194 Interested parties had only forty-seven days to comment on the entire rule, followed by a thirteen-day public hearing. ${ }^{195}$

The appeals court reversed the regulation due to the agency's failure to make a separate scientific case for each individual substance's health risks. ${ }^{196}$ While acknowledging that the rulemaking may have been "the only practical way of accomplishing a much needed revision," the court nonetheless expressed skepticism about the agency's method for doing so - even accusing the agency of being "misleading" in labeling its regulation as "generic." 197 In addition, the agency's proffered reasons — namely, the need for expediency — were candid, but unmoored from the evidentiary record. ${ }^{198}$ Furthermore, the court complained that the agency's extreme bundling stymied judicial review. ${ }^{199}$ As a result, the opinion was only able

final rules, which have been combined to reduce the impact and number of times certain compliance activities need to be undertaken by the regulated entities.").

190965 F.2d 962.

${ }^{191} I d$. at 970 ("“Substantial evidence' is 'such relevant evidence as a reasonable mind might accept as adequate to support a conclusion.' ... 'Under this test, “we must take a 'harder look' at OSHA's action than we would if we were reviewing the action under the more deferential arbitrary and capricious standard applicable to agencies governed by the Administrative Procedure Act."') (citations omitted).

192 Id. $\$$ 655(a).

193965 F.2d 962.

${ }^{194} \mathrm{Id}$.

${ }^{195}$ Id.

${ }^{196} \mathrm{Id}$.

${ }^{197}$ Id. at 972 (noting that "the new Air Contaminants Standard is an amalgamation of 428 unrelated substance exposure limits" where "[ $\mathrm{t}]$ here is little common to this group of diverse substances except the fact that OSHA considers them toxic and in need of regulation").

${ }^{198} I d$.

${ }^{199} I d$. at 986 ("OSHA has lumped together substances and affected industries and provided such inadequate explanation that it is virtually impossible for a reviewing court to determine if sufficient evidence supports the agency's conclusions."). 
to provide representative problems with the rule and could not address each of its flaws. ${ }^{200}$

Interestingly, arbitrariness review has also been used by courts to set aside rules that fail to consider other rules that are closely related. In Spirit of Sage Council v. Norton, ${ }^{201}$ for instance, a district court reviewed two rules issued by the Fish and Wildlife Service (FWS) and other agencies pursuant to the Endangered Species Act. The first rule, the "No Surprises Rule," provided that landowners who submit a habitat conservation plan would not be required to make additional financial resources or commit to additional restrictions on property use, so long as they abided by the terms of the plan. A subsequent regulation, the "Permit Revocation Rule" provided that the assurance of no surprises could be revoked under certain circumstances. Without identifying any substantive deficiencies, the court held that the two rules were "sufficiently intertwined" and thus had to be remanded so that the agencies could jointly consider the related provisions. ${ }^{202}$ After the D.C. Circuit denied the FWS's motion for a stay pending appeal, the agencies bundled the rules and solicited comments on what had previously been two separate rulemakings. ${ }^{203}$

\section{b. Notice and Logical Outgrowth}

Beyond arbitrariness review, courts can also play an important role in ensuring that bundling rules provide sufficient notice to public commenters. Courts must ensure that those who seek to participate in a rulemaking are given sufficient warning about an agency's regulatory proposals. ${ }^{204}$ Recall OSHA's rulemaking regulating 428 different substances. During litigation, industry groups complained that bundling so many substances into a single rule impeded their ability to raise all their concerns. ${ }^{205}$ They complained that too many issues were presented with less than fifty days to comment on all of them. On the facts and statutory background of $A F L-C I O$ v. OSHA, the court dismissed this concern. ${ }^{206}$ But one could imagine the adequacy of notice playing an important part of judicial review, especially as agencies appear to be bundling at higher rates.

Yet another related concern stems from the connection between the proposed rule and the final rule. If the final rule is so different from the proposal, that is not a "logical outgrowth" of it, then commenters may not have had the adequate ability to participate - they were not sufficiently on notice of what the agency might do. ${ }^{207}$

\footnotetext{
${ }^{200} I d$. (noting that " $[\mathrm{t}]$ he individual substances discussed in this opinion are merely examples of what is endemic in the Air Contaminants Standard as a whole").

201411 F.3d 225 (D.C. Cir. 2005).

202 Spirit of Sage Council v. Norton, 294 F. Supp. 2d 67, 91 (D.D.C. 2003).

203 Final Rule, 69 Fed. Reg. 71,723 (Dec. 10, 2004).

2045 U.S.C. $\$ 553$ (requiring a "notice" of proposed rulemaking).

205965 F.2d at 969, n.8.

${ }^{206} \mathrm{Id}$.

207 See, Small Refiner Lead Phase-Down Task Force v. EPA, 705 F.2d 506, 547 (D.C. Cir. 1983); Sierra Club v. Costle, 657 F.2d 298, 352 (D.C. Cir. 1981); Shell Oil Co. v. EPA, 950 F.2d 741, 759 (D.C. Cir. 1991).
} 
Courts have been using the logical outgrowth doctrine to police the concern that final rules will be written in ways that could not be anticipated by would-be commenters. ${ }^{208}$ The worry is that agencies could keep their intended rules under wraps while proposing something only tenuously related to what they plan to impose. ${ }^{209}$ This doctrine may thus be another tool through which courts police bundling, particularly if agencies tend to increase bundling through the notice and comment process.

While the above tools are important to consider in the administrative state, whether they should be adopted still requires empirical work beyond the scope of this paper as to why regulatory bundling occurs. One study might investigate, for example, whether OIRA's line-item veto in fact resulted in more burdensome regulations as a result of the incentive to add costlier provisions for negotiation purposes. Such a finding could lend support to the conclusion that bundling should be constrained. Most likely, there are multiple explanations and consequences in practice, which may instead necessitate a more case-by-case assessment.

On the one hand, as noted above, regulatory bundling can reflect a strategic attempt by an agency to obfuscate or otherwise overwhelm the monitors of a particular rulemaking. The associated concerns, then, would be that unelected bureaucrats are making policy without democratic accountability or due process values like notice and participation. On the other hand, regulatory bundling may also have more salutary motivations and consequences. For example, it may reflect deliberative compromises between agency actors and members of Congress or the White House. ${ }^{210}$ Such deliberation may result in more information, creative policymaking and public-regarding results. ${ }^{211}$ It may also help facilitate rulemaking when parties with unrepresentative or extreme preferences otherwise attempt to block welfare-enhancing regulation. In this sense, bundling can serve as a kind of commitment device. ${ }^{212}$ As previously noted, bundled rules could also help to

\footnotetext{
${ }^{208}$ See, e.g., CSX Transp., Inc. v. Surface Transp. Bd., 584 F.3d 1076, 1080 (D.C. Cir. 2009). See generally Jack M. Beermann \& Gary Lawson, Reprocessing Vermont Yankee, 75 GEO. WASH. L. REV. 856, 899 (2007).

209 See $i d$.

${ }^{210}$ Cf. Mark Seidenfeld, A Civic Republican Justification for the Bureaucratic State, 105 HARV. L. REV. 1511 (1992).

${ }^{211} I d$.

${ }^{212}$ During negotiations over the proposed rule, the inability of an agency to commit to a particular deal is a problem that could undo many attempted compromises. An agency might, for example, attempt to placate an interest group by promising some favored regulatory revision in the future. The interest group may not trust the agency to follow through, however: after all, there might be a change in agency personnel, or a shift in priorities due to exogenous events. As a result, the interest group may challenge the immediate rule and thereby delay its implementation for years. Instead, the agency may bundle the change into the final rule. This transparently allows the agency to credibly commit to the revision, thus forestalling whatever adverse action contemplated by the interest group or political actor. See JON ElSTER, UlySSES UNBOUND: STUDIES IN RATIONALITY, PRECOMMITMENT, AND CONSTRAINTS 88-92 (2000).
} 
decrease compliance costs by allowing regulated entities to comply more efficiently through one-time technological investments. Bundling can also increase predictability and certainty about an agency's policy choices regarding a particular regulatory problem. For all these reasons, a normative appraisal of regulatory bundling requires further empirical examination of the aggregate consequences of the phenomenon. In the meantime, more case-by-case evaluations of the practice's tradeoffs would also be valuable.

\section{Conclusion}

Administrative agencies can aggregate and disaggregate their policymaking instruments. This Article has explored how they do so with respect to legislative rules. It has identified the concept of regulatory bundling and proposed a way to operationalize it. The empirical analysis suggests that regulatory bundling is an increasingly common phenomenon. At the same time, agency practices vary widely - some bundle frequently, others rarely. Most agencies, however, appear to bundle more as the rulemaking process unfolds, that is, they bundle more issues into final rather than proposed rules. These findings, in turn, raise significant normative concerns that may be addressed through a suite of tools novel to the administrative state: single-subject rules, line-item vetoes, and innovative forms of judicial review.

More broadly, this work has sought to open up further lines of inquiry analogous to those explored by social scientists in the legislative context. Indeed, many research questions remain: What aspects of agency variation explain differences in bundling behavior? Does regulatory bundling as a whole increase or decrease social welfare? Relatedly, has OIRA's line-item veto resulted in more or less regulatory costs? While administrative law has long allowed agencies flexibility in choosing their policymaking tools, the law's normative concerns with notice and participation require further scrutiny over how these tools are aggregated and disaggregated in practice. 


\section{Appendix}

\section{Basic Summary Statistics}

Table A1: Summary Statistics, 2000-17

\begin{tabular}{lccccc}
\hline \hline & & \multicolumn{4}{c}{ Subjects } \\
& No. of Obs. & Mean & Std. Dev. & Max & Min \\
\hline NPRMs & 40823 & 4.45 & 3.14 & 41 & 0 \\
Final Rules & 18898 & 4.67 & 3.54 & 62 & 0 \\
\hline
\end{tabular}

\section{Table of Agency Abbreviations}

\begin{tabular}{|l|l|}
\hline Abbreviation & \multicolumn{1}{|c|}{ Agency Name } \\
\hline AID & Agency for International Development \\
\hline ATBCB & $\begin{array}{l}\text { Architectural and Transportation Barriers Compliance } \\
\text { Board }\end{array}$ \\
\hline CFPB* & Bureau of Consumer Financial Protection \\
\hline CFTC* & Commodity Futures Trading Commission \\
\hline CNSC & Corporation for National and Community Service \\
\hline CPSC & Consumer Product Safety Commission \\
\hline DHS & Department of Homeland Security \\
\hline DOC & Department of Commerce \\
\hline DOD & Department of Defense \\
\hline DOE & Department of Energy \\
\hline DOI & Department of Interior \\
\hline DOJ & Department of Justice \\
\hline DOL & Department of Labor \\
\hline DOS & Department of State \\
\hline DOT & Department of Transportation \\
\hline ED & Department of Education \\
\hline EEOC & Equal Employment Opportunity Commission \\
\hline EPA & Environmental Protection Agency \\
\hline FCA & Farm Credit Administration \\
\hline FCC $*$ & Federal Communications Commission \\
\hline FDIC* & Federal Deposit Insurance Corporation \\
\hline FEC & Federal Election Commission \\
\hline FERC $*$ & Federal Energy Regulatory Commission \\
\hline FHFA & Federal Housing Finance Agency \\
\hline &
\end{tabular}




\begin{tabular}{|l|l|} 
FHFB & Federal Housing Finance Board \\
\hline FLRA & Federal Labor Relations Authority \\
\hline FMC* & Federal Maritime Commission \\
\hline FRB* & Federal Reserve System, Board of Governors \\
\hline FRTIB & Federal Retirement Thrift Investment Board \\
\hline FTC & Federal Trade Commission \\
\hline GSA & General Services Administration \\
\hline HHS & Department of Health and Human Services \\
\hline HUD & Department of Housing and Urban Development \\
\hline ITC & United States International Trade Commission \\
\hline LSC & Legal Services Corporation \\
\hline MSPB & Merit Systems Protection Board \\
\hline NARA & National Archives and Records Administration \\
\hline NASA & National Aeronautics and Space Administration \\
\hline NCUA & National Credit Union Administration \\
\hline NFAH & National Foundation on the Arts and the Humanities \\
\hline NIGC & National Indian Gaming Commission \\
\hline NLRB & National Labor Relations Board \\
\hline NRC* & Nuclear Regulatory Commission \\
\hline NSF & National Science Foundation \\
\hline NTSB & National Transportation Safety Board \\
\hline OCC* & Office of the Comptroller of the Currency \\
\hline OGE & Office of Government Ethics \\
\hline OMB & Office of Management and Budget \\
\hline OPM & Office of Personnel Management \\
\hline PBGC & Pension Benefit Guaranty Corporation \\
\hline PRC* & Postal Rate Commission \\
\hline RRB & Railroad Retirement Board \\
\hline SBA & Small Business Administration \\
\hline SEC* & Securities and Exchange Commission \\
\hline SSA & Social Security Administration \\
\hline STB & Social Security Administration \\
\hline TRE & Department of Treasury \\
\hline TVA & Tennessee Valley Authority \\
\hline USDA & Department of Agriculture \\
\hline USPS & United States Postal Service \\
\hline VA & Department of Veterans Affairs \\
\hline Note: An asterisk (*) denotes an “independent" agency, as classified in the \\
These agencies ofter often engaged in little rulemaking.
\end{tabular}




\section{Data Preparation}

The Government Printing Office (GPO) makes XML files of the Federal Register available between the year 2000 and the present. We download those files and, initially, capture all entries in the Proposed Rule and Rules and Regulations sections of the files. Not all entries in those sections, however, were proposed rules or final rules. For instance, the proposed rule section also contained notices of hearings and other intermediate procedural components. Moreover, we sought to focus on legislative rules, and thus we had to screen out non-legislative rules such as interpretative rules, and rules of agency procedure.

To do so, we adopted a two-step procedure. First, under the Office of the Federal Register's Document Drafting Handbook, ${ }^{213}$ proposed and final rules must contain "words of issuance." In the case of proposed rules, these words, as the Handbook states, represent an "expression that connects the preamble to the regulatory text and the tie between the proposed rule and the CFR units you propose to change." ${ }^{214}$ This is a helpful textual cue, as most non-legislative actions do not affect the CFR, and therefore would not contain words of issuance; by contrast, virtually all legislative rules would affect the CFR and therefore would contain words of issuance. The words of issuance, the Handbook continues, are "always in the present tense and use the word 'propose' or 'proposes," 215 and advises that the relevant verbs are "amend," "add," "revise," and "remove." Examples in the Handbook include, "For the reasons discussed in the preamble, the Nuclear Regulatory Commission proposes to amend 10 CFR part 430 as follows:", and "For the reasons discussed in the preamble, the Federal Communications Commission proposes to revise 47 CFR part 430 to read as follows:". We detect these words of issuances using a regular expression that searches for some variant of "propose" near one of those verbs, followed by a reference to the CFR or Code of Federal Regulations. As a first screen, we remove those entries in the proposed rules section of the Federal Register that do not contain words of issuance. The Handbook also contains instructions for final rules, and we apply the same basic methodology in the rules and regulations section of the Federal Register.

This words of issuance screen removes most entries not related to legislative rulemakings. However, some non-legislative rules do affect the CFR, and we therefore want a secondary screen. In particular, rules of agency procedure often change the CFR. As a secondary screen, therefore, we examine the titles of the rulemaking efforts and remove any title that refers to "procedure" or "procedural."

This two-step procedure removes a substantial number of entries in the Federal Register. In all, the original, unscreened dataset contained roughly 43,500 entries in the proposed rule section and 68,000 entries in the rules and regulations section. The words of issuance screen removes over 24,000 entries from the proposed rule section and about 25,500 entries from the rules and regulations

\footnotetext{
${ }^{213}$ https://www.archives.gov/files/federal-register/write/handbook/ddh.pdf

${ }^{214} \mathrm{Id}$. at 2-16.

${ }^{215} I d$.
} 
section. The procedural rule screen removes a further 400 entries from the proposed rule section and about 1,700 entries from the rules and regulation section.

\section{Redundancy-Adjusted Measure}

Under the Office of Federal Register's Thesaurus of Indexing Terms, many of the subjects exist in a hierarchical relationship to other subjects, with more precise terms falling under more general terms. For instance, "air taxis" is a specific example of "air transportation," and both terms exist as permissible entries in the thesaurus that agencies might list in their rules. When agencies list both terms, the number of listed subjects may greater than the number of true subjects in a meaningful way. Some of the listed subjects, that is, are redundant: adding a broader term to a more specific term does not increase the number of subjects addressed in a rulemaking effort. To account for this possibility, we wish to develop a redundancy-adjusted measure of the number of subjects.

There are various ways that one might address this problem. A standard technique in natural language processing involves reducing the dimensionality of the word-space using, for instance, singular value decomposition or topic modeling. Likewise, scholars often attempt to reduce a large set of variables to a smaller set of factors using principal components analysis or similar techniques. Doing so facilitates subsequent statistical analysis and may make the data more interpretable. Also related, in financial analysis, many measures of portfolio diversification exist, all of which provide some sense of how much "overlap" there is a portfolio, a question not far from the present interest.

All of these techniques also have downsides. For instance, one generally must select the number of factors or topics to model when reducing the dimensionality of the data. Algorithms and rules of thumb exist to help select the number of factors, but it is impossible to escape a degree of arbitrariness. More important, introducing a reduced-dimensionality representation of the data can in fact impede intuition and interpretation - it is often not clear what the various factors or topics produced by these techniques refer to. Nor, importantly, is it obvious how to produce from these reduced-dimensionality representations an intuitive sense of how "many" subjects a given rule relates to. Most importantly, however, these techniques do not take advantage of the structure known to exist in the data: the thesaurus tells us about the relationship between more specific and more general terms.

To adjust the number of subjects, we adopt a simple algorithm that exploits the fact that the thesaurus informs us of the semantic structure of the terms. Consider the thesaurus entry for "air transportation." It reads as follows:

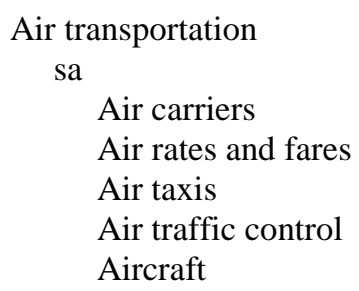


Airmen
Airports
Airspace
Aviation safety
Charter flights
Military air transportation
Navigation (air)

where "sa" is used by the thesaurus to "[r]eference user to narrower and related terms." 216 This structure, therefore, tells us that "air taxis" is a more specific term under the heading of "air transportation." Using this structure, first, we convert the thesaurus into a database in which each list "general" term is associated with any relevant more "specific term." Second, we examine each listed subject for each rule, probe whether it is a general term, and if so determine whether any of the specific terms listed by the agency appear as separate entries for that rule. If so, we depreciate the general term from the count of the number of subjects for that rule. If not, we retain the general term, as no more specific substitute exists in the list of subjects for that rule. To take an example, if the rule listed "air taxis" and "air transportation," our simple algorithm would produce a count of one, as we effectively remove "air transportation" from the list of subjects. At the same time, if it listed only "air taxis" or only "air transportation," the count would likewise be one.

It turns out that agencies commonly list both more general and more specific terms, but that it does not affect the qualitative features of the data. For instance, nearly 60 percent (roughly 66,500) of the final or proposed rules in the dataset require the depreciation of at least one general term. However, the adjusted and unadjusted measures correlated strongly, $r=0.96$. As robustness exercises, we reestimate the empirical analyses presented in the body of this Article. Qualitatively, the results do not change under the adjusted measure, and we make them available on request.

\section{Evaluating Strategic Subject Reporting}

Our measure of bundling behavior relies on the subjects that the agency itself lists as relevant to the rulemaking effort. One concern with this approach is that these self-reports may be strategic, that is, that agency officials may obscure the subjects of the rule when facing an oppositional oversight or litigation environment. At the same time, such strategic behavior is likely limited by the layers of review, including by the Office of the Federal Register. To probe the extent to which the number of subjects may be subject to strategic reporting, one can examine transitions in the oversight environment for changes in reporting behavior. The oversight environment, of course, may change the underlying substantive rulemaking efforts as well, however, and this makes it necessary to account for such substantive changes. We account for substantive changes by examining the number of CFR sub-Parts cited by the agency as relevant to the rulemaking effort: this measure is theoretically (and

216 OFFICE OF THE FEDERAL REGISTER, HISTORY OF THE THESAURUS OF INDEXING TERMS AND THE CFR INDEX. 
empirically) correlated with the number of subjects listed, but is in principle much more difficult to manipulate as it ties closely to the legal provisions that the agency wishes to amend. To the extent the list of subjects is strategically manipulated, one would want to see changes in the number of subjects listed around these transitions, beyond what might be expected based on changes to the underlying substance of the regulations.

To provide some sense of this issue, consider the transitions following the 2006 and 2010 elections. The 2006 election saw the Democrats win control of both chambers of Congress when George W. Bush was president. In the 2010 election, the coordinates flip: we have a Democratic president, and a Congress that transitions from Democratic control to Republican control. We can arrive an estimate of how subjects change relative to CFR sub-Parts via the following equation:

$$
\operatorname{Sub}_{i}=\alpha+\beta 1 \text { Subparts }_{i}+\beta_{2} \text { Trans }_{i}+\beta_{3} \text { Subparts }_{i} \text { XTrans }_{i}+\epsilon_{i}
$$

where $S u b_{i}$ is the number of subjects listed in document $i$, Subparts $_{i}$ is the number of CFR sub-Parts in that document, and $\operatorname{Trans}_{i}$ is an indicator that takes a 1 if the notice or rule is issued after the transition and a 0 otherwise. The coefficient on the interaction term informs us of the extent to which the relative relationship between subjects and subparts changes following the transition. If agencies manipulate the subjects, one ought to see shifts in this relationship, as agencies add or remove subjects relative to the number of CFR sub-Parts in response to the change in the oversight environment; on the other hand, if there is little manipulation, the interaction term should be close to zero. For all elections, we subset the data on the June-to-June period around the transition, e.g., from June 2006 to June 2007, in the case of the transition following the 2006 election.

Table A3 reports the results from this exercise, with separate specifications for proposed and final rules in 2006 and 2010. The results can be summarized succinctly: in no case does the critical interaction term return with a statistically significant coefficient. This suggests that, whatever the relationship between the underlying CFR sub-parts and the number of subjects, it remained essentially unaffected by the transition in congressional oversight. This weighs against the idea that agencies behave very strategically or manipulate the list of subjects. 
Table A3: Manipulation Checks

\begin{tabular}{|c|c|c|c|c|}
\hline & \multicolumn{2}{|c|}{2006} & \multicolumn{2}{|c|}{2010} \\
\hline & NPRM & Final Rule & NPRM & Final Rule \\
\hline \multirow[t]{2}{*}{ Constant } & 4.35 & 4.37 & 4.62 & 4.71 \\
\hline & $(0.26)$ & $(0.3)$ & $(0.28)$ & $(0.36)$ \\
\hline \multirow[t]{2}{*}{ Sub-Parts } & 0.01 & 0 & 0.02 & 0.01 \\
\hline & $(0.01)$ & $(0)$ & $(0.01)$ & $(0.01)$ \\
\hline \multirow[t]{2}{*}{ Transition } & -0.02 & 0.2 & 0 & 0 \\
\hline & $(0.23)$ & $(0.22)$ & $(0.24)$ & $(0.13)$ \\
\hline \multirow[t]{2}{*}{ Sub-Parts X Transition } & 0 & 0.01 & 0.04 & 0 \\
\hline & $(0.01)$ & $(0.01)$ & $(0.03)$ & $(0.01)$ \\
\hline $\mathrm{N}$ & 1088 & 2530 & 1201 & 2476 \\
\hline R-squared & 0.01 & 0.01 & 0.03 & 0.005 \\
\hline
\end{tabular}

Standard errors clustered by agency and reported in parentheses. 